\title{
GCU
}

Glasgow Caledonian

University

University for the Common Good

\section{Bee-foraging learning particle swarm optimization}

Chen, Xu; Tianfield, Hugo; Du, Wenli

Published in:

Applied Soft Computing

DOI:

10.1016/j.asoc.2021.107134

Publication date:

2021

Document Version

Author accepted manuscript

Link to publication in ResearchOnline

Citation for published version (Harvard):

Chen, X, Tianfield, H \& Du, W 2021, 'Bee-foraging learning particle swarm optimization', Applied Soft Computing, vol. 102, 107134. https://doi.org/10.1016/j.asoc.2021.107134

\section{General rights}

Copyright and moral rights for the publications made accessible in the public portal are retained by the authors and/or other copyright owners and it is a condition of accessing publications that users recognise and abide by the legal requirements associated with these rights.

Take down policy

If you believe that this document breaches copyright please view our takedown policy at https://edshare.gcu.ac.uk/id/eprint/5179 for details of how to contact us. 


\title{
Bee-foraging learning particle swarm optimization
}

\author{
Xu Chen ${ }^{\mathrm{a}, *}$, Hugo Tianfield ${ }^{\mathrm{b}}$, Wenli $\mathrm{Du}^{\mathrm{c}}$ \\ ${ }^{a}$ School of Electrical and Information Engineering, Jiangsu University, Zhenjiang 212013, Jiangsu, China; \\ ${ }^{b}$ School of Computing, Engineering and Built Environment, Glasgow Caledonian University, Glasgow G4 OBA, \\ $U K$ \\ ${ }^{c}$ Key Laboratory of Advanced Control and Optimization for Chemical Processes, Ministry of Education, East \\ China University of Science and Technology, Shanghai, 200237, China
}

\begin{abstract}
Numerous particle swarm optimization (PSO) algorithms have been developed for solving numerical optimization problems in recent years. However, most of existing PSO algorithms have only one search phase. There is no strengthened search phase for the well-performed particles, and also no re-initialization phase for the exhausted particles. These issues may still restrict the performance of PSO for complex optimization problems. In this paper, inspired by the beeforaging search mechanism of artificial bee colony algorithm, a novel bee-foraging learning PSO (BFL-PSO) algorithm is proposed. Different from existing PSO algorithms, the proposed BFLPSO has three different search phases, namely employed learning, onlooker learning and scout learning. The employed learning phase works like traditional one-phase-based PSO, while the onlooker learning phase performs strengthened search around those well-performed particles to exploit promising solutions, and the scout learning phase re-initializes those exhausted particles to introduce new diversity. The proposed BFL-PSO is comprehensively evaluated on CEC2014 benchmark functions, and compared with state-of-the-art PSO algorithms as well as artificial bee colony algorithms. The experimental results show that BFL-PSO achieves very competitive performance in terms of solution accuracy. In addition, the effectiveness of the newly introduced onlooker learning and scout learning phases in BFL-PSO is verified.
\end{abstract}

Keywords: Particle swarm optimization, bee-foraging learning mechanism, artificial bee colony, numerical optimization

\footnotetext{
${ }^{*}$ Corresponding author

Email address: xuchen@ujs.edu.cn (Xu Chen )
} 


\section{Introduction}

Particle swarm optimization (PSO) is a swarm intelligence algorithm originally proposed by Kennedy and Eberhart, inspired by the social behavior of bird swarm in search of destination. In PSO, each particle has its velocity and position, and also memorizes its own best position found in history. By using the information from the personal best and global best positions, each particle adjusts its velocity and position to search for optimal solution [I]. PSO has attracted much attention in the past two decades due to its easy implementation, conceptual simplicity and rapid convergence, and has also been successfully applied for solving optimization problems in many areas [2], $3, \mathbf{3}, \mathbf{4}, \mathbf{5}]$.

PSO shows promising performance in many optimization problems, however, it often suffers from premature convergence and stagnation in the search process. To enhance the performance, many improved PSO variants have been proposed, such as CLPSO (comprehensive learning PSO) [6], OLPSO (Orthogonal learning PSO) [7], SLPSO (social learning PSO) [8], SRPSO (self-regulating PSO) [9], EPSO (ensemble PSO) [10], BLPSO (biogeography-based learning PSO) [I]], GLPSO (genetic learning PSO) [II2], FMPSO (fitness-based multi-role PSO) [I3], to name a few.

Although these PSO variants alleviate the drawbacks of the PSO to a certain extent, most of them do not include strengthened search strategy for those particles that perform well during the searching process. On the other hand, these particles which have not improved their fitness over a certain number of iterations may have suffered from stagnation, and no strategy is used to handle this situation. These issues may still restrict the performance of PSO for solving complex global optimization problems (GOPs).

Artificial bee colony $(\mathrm{ABC})$ is another swarm intelligence algorithm inspired by the bee foraging behavior [14]. ABC has division-of-labor feature that is different from the other swarm-based meta-heuristics including PSO and ant colony optimization [15]. Specifically, the optimization process of $\mathrm{ABC}$ simulates three different groups of bees, that is, employed bees, onlookers, and scouts, searching for food sources [ㅍ]. Employed bees search around the food sources to seek for better ones, onlooker bees perform strengthened search around those food sources with better fitness, and scout bees perform random search when the exhausted food sources are identified.

In this paper, by integrating the bee-foraging search mechanism into PSO, we develop a novel bee-foraging learning PSO (BFL-PSO) algorithm. Different from existing PSO algorithms, BFL-PSO involves three kinds of search phases, namely employed learning, onlooker learning and 
scout learning. The employed learning plays a role as the traditional single-phase-based PSO, while the onlooker learning and scout learning are two new search phases which do not exist in traditional PSO. The onlooker learning performs strengthened search around those particles with better fitness for exploitation, while the scout learning re-initializes the velocities and positions of those exhausted particles for exploration. The proposed BFL-PSO algorithm is evaluated on CEC2014 benchmark functions [I7] in comparison with the state-of-the-art PSO algorithms as well as ABC algorithms to verify its performance.

The remainder of this paper is organized as follows. Section 2 presents the literature review. Section 3 proposes a bee-foraging learning PSO (BFL-PSO) algorithm. Section 4 provides the experimental results and comparisons. Section 5 applies the BFL-PSO algorithm to solve economic power dispatch problems. Finally, Section 6 concludes this paper.

\section{Literature review}

Numerous PSO algorithms have been developed in the past two decades. In this section, we provide a brief review on the recently well-established PSO algorithms. For a more comprehensive review of past PSO, please refer to [II8] and [I.9] .

\subsection{PSO with parameter control mechanisms}

PSO has control parameters including inertia weight, acceleration coefficients and and population size, and properly setting these parameters may largely improve PSO's performance. In [9], inspired from the human cognitive psychology, a self-regulating PSO (SRPSO) algorithm was developed, which employed a self-regulating inertia weight for the best particle to improve the exploration. In [13], a fitness-based multi-role PSO (FMPSO) algorithm was proposed with multi-role-based parameter mechanism. Based on the fitness values, the particles in FMPSO play three different roles (leader, rambler and follower), and different inertia weights and acceleration coefficients are set for different roles, which helps the population perform different search patterns. In [20], according to its distance to personal best position, each particle uses different inertia weights in different dimensions. Moreover, the acceleration coefficients are calculated adaptively according to a stability condition. In [2]], a hybrid PSO with sine cosine acceleration coefficients (HPSOSCAC) was proposed, in which sine cosine based acceleration coefficients efficiently controls the local search and convergence to global optimal solution. In [22], a population size adaptive mechanism was designed for PSO, in which two operators namely deleting particles and adding particles are performed during the evolutionary process. When the fitness landscape 
is easy to optimize, some bad particles are deleted, while when the population cannot find more promising solutions, some pleasurable particles are added to the population.

\subsection{PSO with population topology or multi-swarm}

Population topology and multi-swarm techniques can help enhance the population diversity, which may help improve PSO's performance for complex multimodal problems. In [2:3], the ring topology was introduced into genetic learning PSO, and it is shown that replacing the global topology with ring topology for exemplar generation can enhance the diversity and exploratory of genetic learning PSO. In [24], the cellular structured population was employed for quantuminspired PSO (QPSO), and the cQPSO algorithm was proposed. In cQPSO, the particles are distributed in a two-dimensional grid and only interact with their neighbors. In [25], a heterogeneous comprehensive learning PSO (HCLPSO) using two subpopulations was proposed. In HCLPSO, one subpopulation focuses on exploration, while the other focuses on exploration. In [26] , a multi-population cooperative PSO with a mixed mutation strategy (MPCPSO) was proposed. In MPCPSO, the population is divided into elitist sub-population and general subpopulation based on the fitness values. Elitist sub-population and general sub-population adopt different learning strategies, with the objectives of guiding particle evolution and maintaining population diversity, respectively.

\subsection{PSO with new learning strategies}

Designing new learning strategies can utilize the search information more efficiently, and it is another promising way to develop new PSO algorithms. In [8], a social learning mechanism was introduced into PSO to developed a social learning PSO (SLPSO) algorithm. In the social learning mechanism, each particle learns from different better particles in the current swarm, and a dimension-based parameter setting method is used to enhance the algorithmic robustness to the search dimension. In [12], a genetic learning strategy was devised for PSO, which uses genetic evolution operators to breed promising exemplars based on the personal best information. Using the GLS, the global search ability and search efficiency of genetic learning PSO (GLPSO) are both improved. In [푸], inspired by interactive learning behaviors taken place among different human groups, a new PSO algorithm with interswarm interactive learning strategy (IILPSO) was proposed. In IILPSO, the particles are divided into two groups, when the best particle's fitness values of both sub-groups do not improve, the interswarm interactive learning behavior is triggered. In [10], an ensemble leaning method was devised and an ensemble PSO (ESPO) 
algorithm was proposed. In EPSO, based on a self-adaptive mechanism, five different updating strategies are employed to improve the versatility and robustness of PSO for different optimization problems. In [II], a biogeography-based learning PSO (BLPSO) algorithm was proposed, in which each particle updates its position by using all particles' personal best positions through the biogeography-based migration mechanism. In [28], a dimensional learning strategy was devised for PSO, which is used to integrate and discover the promising information among the global best position and the personal best positions of all particles. In [2.9] , a level-based learning mechnism was devised and a level-based learning swarm optimizer (LLSO) was proposed for large-scale global optimization. In LLSO, the particles are divided into several levels according to their fitnes values, and each particle randomly select two predominant particles from two different higher levels to guide the learning.

\subsection{PSO hybrid with non-ABC meta-heuristics}

Many hybrid PSO algorithms have been developed, since hybrid PSO with other metaheuristic algorithms can combine their merits and overcome drawbacks. In [30], teachinglearning-based optimization (TLBO) was introduced into PSO, and a bidirectional teaching and peer-learning PSO (BTPLPSO) algorithm was proposed. In BTPLPSO, the particles that fail to improve their fitness will enter into a peer-learning phase, and learn from the high-quality exemplars. In [3] , cultural evolution algorithm was introduced into quantum-behaved PSO (QPSO), and a cultural quantum-behaved PSO (CMOQPSO) was proposed. In CMOQPSO, a belief space containing three types of knowledge is extracted from the particle swarm and also used to generate global best positions for the particles. In [32], a hybrid PSO algorithm with levy flight (PSOLF) was propsoed. In PSOLF, the levy flight mechanism from cuckoo search algorithm is used for updating the particles' velocities, and it is shown that PSOLF has high convergence rate. In [33], by hybridizing PSO with harmony search, a hybrid algorithm called HHSPSOGDS was proposed. In HHSPSO-GDS, the improvisation mechanism of harmony search and a global dimension selection are incorporated into the algorithm which effectively enhances the convergence. In [34], a hybrid crisscross search PSO (CSPSO) algorithm was proposed, in which the population is updated through crisscross search and PSO in sequence. In [35], a differential mutation strategy was employed to update the three best particles, and and a differential mutation based social learning PSO (DSPSO) was proposed. DSPSO overcomes the shortcoming of unsatisfactory search efficiency in social learning PSO algorithm. 


\subsection{PSO hybrid with artificial bee colony}

The hybridization of PSO and artificial bee colony (ABC) has also attracted researchers' attention, and several hybrid PSO-ABC algorithms have been proposed. Firstly, several hybridizations combine PSO and ABC in a dual-swarm parallel framework. For example, in [36], an integrated algorithm called IABAP was proposed by parallelly executing PSO and ABC algorithms and exchanging the information of two sub-swarms. In [37], a hybrid algorithm called HPA was proposed, where a recombination operator is performed on the best solutions of PSO and ABC, and the obtained solutions are fed back to PSO and ABC. Secondly, several hybridizations combine PSO and ABC in a cascade framework. In [38], an adaptive bee and particle swarm optimization algorithm called ABeePSO was proposed, in which the ABC algorithm is employed to generate the swarm diversity when the PSO algorithm stagnates. In [39], two search phases from $\mathrm{ABC}$ and one local search phase from PSO were combined, and a hybrid algorithm called PS-ABC was proposed. Thirdly, several hybridizations use ABC's search strategy in PSO or use PSO's search strategy in ABC. In [4]], by using the ABC's search strategy on the personal best positions of the standard PSO, a hybrid ABC-SPSO algorithm was proposed. In [41], by using PSO's search equation in bee search phase as well as chaotic search operation on the global best solution, a hybrid algorithm called ABC-PS was proposed. In [42], the concept of velocity was introduced into $\mathrm{ABC}$, and velocity based $\mathrm{ABC}(\mathrm{VABC})$ algorithm was developed. In [43], the global best solution and an elitist archive were used to modify the search equation of $\mathrm{ABC}$, and particle swarm inspired multi-elitist ABC (PS-MEABC) algorithm was developed. In [44], local best and global best solutions were used to modify the search equations of employed bees and onlooker bees, and a lbest-gbest ABC (LGABC) algorithm was developed.

This paper will integrate the bee-foraging search mechanism into PSO, and developed a novel bee-foraging learning PSO (BFL-PSO) algorithm. Therefore, our BFL-PSO algorithm presents a new way that combines PSO and $\mathrm{ABC}$ algorithms.

\section{Proposed bee-foraging learning PSO (BFL-PSO) algorithm}

\subsection{Bee-foraging learning model}

PSO uses a population of particles searching for good solutions. In PSO, each particle has its own position and velocity, and updates itself by learning from the personal best positions and global best position. On the other hand, $\mathrm{ABC}$ employs three kinds of bees (i.e., employed, onlooker and scout) searching for good food sources, and different bees are responsible for different 
tasks [45]. Inspired by the division-of-labor of ABC, this paper proposes a new learning model for PSO, called bee-foraging learning (BFL) model.

In the BFL model, the population firstly initializes $N$ particles; each has its own position $\boldsymbol{x}_{i}$, velocity $\boldsymbol{v}_{i}$ and personal best position $\boldsymbol{p b e s t}_{i}$. Then, it will enter into three learning phases, called employed learning, onlooker learning, and scout learning, as shown in Fig.1.

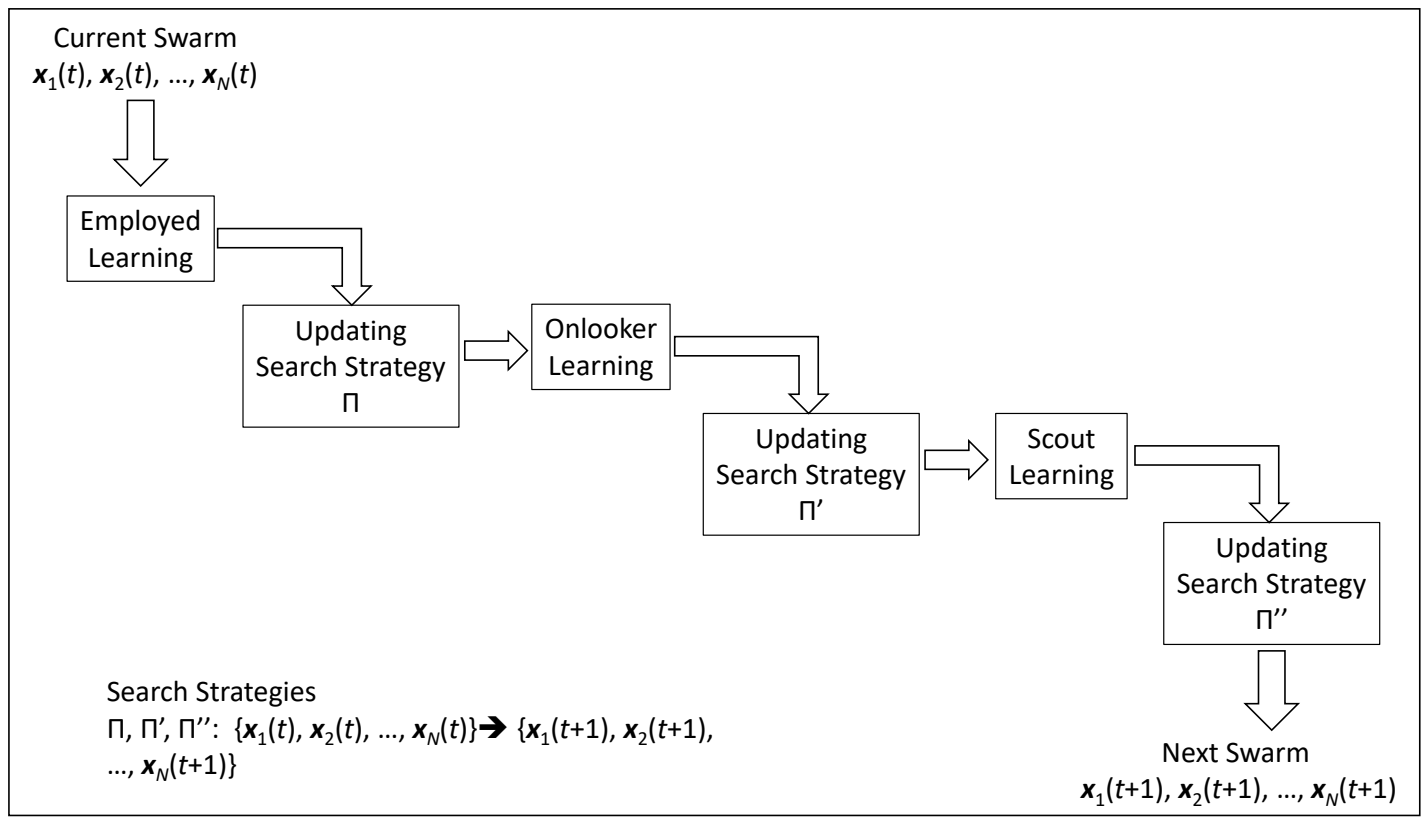

Figure 1: Bee-foraging learning model

\subsubsection{Employed learning}

In the employed learning phase, the particles work like the employed bees in ABC. Specifically, each particle updates its own velocity $\boldsymbol{v}_{i}$ and position $\boldsymbol{x}_{i}$ by learning from the personal best positions (i.e., pbest $_{i}$ ) and global best position (i.e., gbest). The new positions are updated as follow:

$$
\left\{\begin{array}{l}
\boldsymbol{v}_{i}^{\text {new }}=\mu\left(\boldsymbol{v}_{i}^{\text {old }}, \boldsymbol{x}_{i}^{\text {old }}, \text { pbest }_{i}, \text { gbest }\right) \\
\boldsymbol{x}_{i}^{\text {new }}=\boldsymbol{x}_{i}^{\text {old }}+\boldsymbol{v}_{i}^{\text {new }}
\end{array}\right.
$$

where $\boldsymbol{v}_{i}^{\text {old }}$ and $\boldsymbol{x}_{i}^{\text {old }}$ are the velocity and position of the $i$-th particle in previous iteration; $\boldsymbol{v}_{i}^{\text {new }}$ and $\boldsymbol{x}_{i}^{\text {new }}$ are the new velocity and position of the $i$-th particle in current iteration; and function $\mu(\cdot)$ denotes the velocity updating method in PSO. If $\boldsymbol{x}_{i}^{n e w}$ is better than $\boldsymbol{p b e s t}_{i}$ (i.e., $f\left(\boldsymbol{x}_{i}^{\text {new }}\right)<f\left(\boldsymbol{p b e s t}_{i}\right)$, where $f(\cdot)$ is the objective function for a minimization problem), then 
$\boldsymbol{p b e s t}_{i}$ is replaced by $\boldsymbol{x}_{i}^{\text {new }}$.

At the same time, for those particles who fail to update their personal best position $\boldsymbol{p b e s t}_{i}$, their counter will be increased, i.e., $\operatorname{count}(i)=\operatorname{count}(i)+1$, while for those particles who succeed in finding better positions, their counter will be reset, i.e., $\operatorname{count}(i)=0$.

\subsubsection{Onlooker learning}

In the onlooker learning phase, those particles with better fitness are selected to perform strengthened search, which is like the onlooker bees in ABC. The fitness of each particle is firstly calculated based on its $f\left(\right.$ pbest $\left._{i}\right)$ as follows:

$$
f i t\left(\boldsymbol{x}_{i}\right)= \begin{cases}\frac{1}{1+f\left(\text { pbest }_{i}\right)} & \text { if } f\left(\text { pbest }_{i}\right) \geq 0 \\ 1+\mid f\left(\text { pbest }_{i}\right) \mid & \text { otherwise }\end{cases}
$$

and the probability $p_{i}$ for selecting the $i$-th particle is calculated as follows:

$$
p_{i}=\frac{f i t\left(\boldsymbol{x}_{i}\right)}{\sum_{i=1}^{N} f i t\left(\boldsymbol{x}_{i}\right)}
$$

Now, particles are selected based on the probability $p_{i}$ using the roulette method. Those particles with better $\boldsymbol{p b e s t}_{i}$ have larger probability to be selected. Assume the $s$-th particle $\boldsymbol{x}_{s}$ is selected, it will use Eq.(1) to generate a new position $\boldsymbol{x}_{s}^{\text {new }}$. If $\boldsymbol{x}_{s}^{\text {new }}$ is better than $\boldsymbol{p b e s t}_{s}$, then $\boldsymbol{p b e s t}_{s}$ is replaced by $\boldsymbol{x}_{s}^{\text {new }}$.

At the same time, for those particles who fail to update their personal best position pbest $_{s}$, their counter will be increased, i.e., $\operatorname{count}(s)=\operatorname{count}(s)+1$, and for those particles who succeed in finding better positions, their counter will be reset, i.e., $\operatorname{count}(s)=0$.

\subsubsection{Scout learning}

In the scout learning phase, those particles which fail to update their personal best position pbest $_{i}$ in a certain number of iterations (i.e., $\operatorname{count}(i) \geq$ limit) are deemed as exhausted. The particle will be abandoned, and its position $\boldsymbol{x}_{i}$, velocity $\boldsymbol{v}_{i}$ and personal best position $\boldsymbol{p b e s t}_{i}$ are all re-initialized randomly in the search space.

Remark 1: The BFL model incorporates the ABC's division-of-labor feature into PSO. Traditional PSO often has only one learning phase, which is like the employed learning in the BFL model. By contrast, the BFL model introduces two new search phases, i.e., onlooker learning and scout learning. The onlooker learning performs strengthened search around those positions 
with better fitness, which can further enhance the performance of PSO by exploiting promising solutions. The scout learning re-generates the velocities and positions of those exhausted particles, which can bring new diversity when the exhausted particles suffer from stagnation.

\subsection{Description of BLF-PSO Algorithm}

A novel bee-foraging learning PSO (BFL-PSO) algorithm is established based on the BFL model. The velocity and position updating equations of biogeography-based learning PSO (BLPSO) [II] are employed in the BFL-PSO algorithm. The velocity and position updating equations in BFL-PSO are as follows:

$$
\left\{\begin{array}{l}
\boldsymbol{v}_{i}^{\text {new }}=w \cdot \boldsymbol{v}_{i}^{\text {old }}+c \cdot \boldsymbol{r a n d} \cdot\left(\text { pbest }_{\tau_{i}}-\boldsymbol{x}_{i}^{\text {old }}\right) \\
\boldsymbol{x}_{i}^{\text {new }}=\boldsymbol{x}_{i}^{\text {old }}+\boldsymbol{v}_{i}^{\text {new }}
\end{array}\right.
$$

where $w$ is the inertia weight; $c$ is the learning factor; rand is a random vector uniformly distributed within $[0,1]^{D} ; \boldsymbol{\tau}_{i}=\left[\tau_{i}(1), \cdots, \tau_{i}(d), \cdots, \tau_{i}(D)\right]$ is the index vector of learning exemplar for the $i$-th particle, which is generated by biogeography-based exemplar generation method as described in Appendix 1.

The pseudocode of the BFL-PSO algorithm ${ }^{\text {W }}$ is presented in Algorithm 1. In Algorithm $\mathbf{1}$, lines $5 \sim 15$ is the pseudocode of employed learning phase, which is the same as the traditional one-phase-based BLPSO. Lines 16 29 is the pseudocode of onlooker learning phase, and lines $30 \sim 36$ is the pseudocode of scout learning phase.

\footnotetext{
${ }^{1}$ In BFL-PSO, the learning exemplar indices $\boldsymbol{\tau}_{i}$ for the particles are re-generated when there is a stagnation for $G$ continuous iteration, which is helpful for saving computational costs.
} 


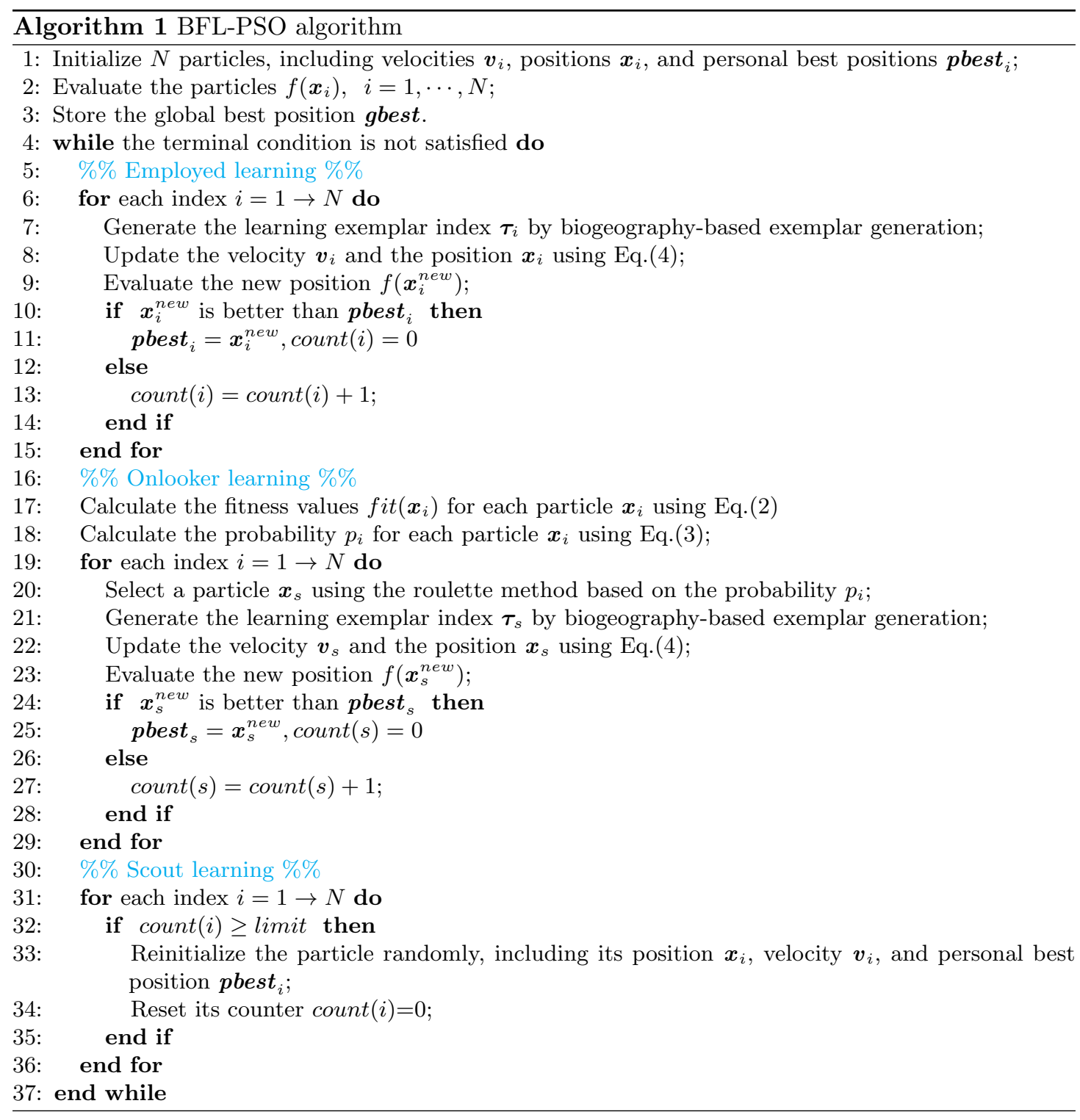

\section{Performance Evaluations}

In this section, the performance of the proposed BFL-PSO algorithm is evaluated on the CEC2014 benchmark functions. These functions have complex properties such as ruggedness, noise in fitness, multimodality, ill-conditioning, interdependence and non-separability. These functions include unimodal functions (F01 F03), simple multimodal functions (F04 F16), hybrid functions (F17 F22) and composite functions (F23 F30). The detail formulations of CEC2014 benchmark functions can be found in [I7]. 
The experimental studies include seven parts:

(1) Subsection 4.1 presents the parameter analysis for BFL-PSO.

(2) Subsection 4.2 analyzes the effectiveness of two new search phases introduced in BFL-PSO.

(3) Subsection 4.3 compares BFL-PSO with five state-of-the-art PSO algorithms.

(4) Subsection 4.4 compares BFL-PSO with five well-established ABC algorithms.

(5) Subsection 4.5 compares BFL-PSO with two hybrid PSO-ABC algorithms.

(6) Subsection 4.6 presents the Friedman rank test and time complexity analysis.

(7) Subsection 4.7 presents the convergence analysis.

The information for the compared algorithms is presented in Table 1, and the parameter settings are presented in Table 2, which are based on the corresponding literature. Moreover, each algorithm is run 51 times independently. The maximum number of function evaluations $(\max F E S)$ is set to be $10000 \times D$, i.e., 300000 for $D=30$, where $D$ is the problem dimension. The mean and standard deviations of the function error values are employed to evaluate the solution accuracy and robustness. Moreover, nonparametric statistical test methods are conducted on the experimental results to reach a reliable statistic conclusion.

Table 1: List of the compared algorithms

\begin{tabular}{|c|c|c|c|}
\hline No. & Abbreviation & Full name & literature \\
\hline 1 & BFL-PSO & Bee-foraging learning PSO & This work \\
\hline 2 & CLPSO & Comprehensive learning PSO & Liang et al. [ [ᄒ] \\
\hline 3 & SRPSO & Self regulating PSO & Tanweer et al. $[9]$ \\
\hline 4 & SLPSO & Social learning PSO & Cheng et al. [8] \\
\hline 5 & EPSO & Ensemble PSO & Lynn et al. [III] \\
\hline 6 & BLPSO & Biogeography-based learning PSO & Chen et al. [II] \\
\hline 7 & $\mathrm{ABC}$ & Artificial bee colony & Karaboga et al. [46] \\
\hline 8 & GABC & Gbest-guided ABC & Zhu et al. [47] \\
\hline 9 & qABC & Quick ABC & Karaboga et al. [48] \\
\hline 10 & ABCVSS & ABC with variable search strategy & Kiran et al. [4.9] \\
\hline 11 & DFSABC & $\begin{array}{l}\text { ABC with depth-first search framework and } \\
\text { elite-guided search equations }\end{array}$ & Cui et al. $[50]$ \\
\hline 12 & PS-MEABC & Particle swarm inspired multi-elitist ABC & Xiang et al. [4.3] \\
\hline 13 & PS-ABC & Hybrid particle swarm and $\mathrm{ABC}$ & Li et al. [3.9] \\
\hline
\end{tabular}


Table 2: Parameter settings for the compared algorithms

\begin{tabular}{|c|c|c|}
\hline No. & Algorithm & Parameter settings \\
\hline 1 & BFL-PSO & $\begin{array}{l}\text { population size } N=40 \text {, inertia weight } w=0.9 \sim 0.2 \text {, acceleration coefficient } c=1.49445 \text {, } \\
\text { maximum migration rates } I=E=1 \text {, refreshing gap } G=5 \text {, limit }=0.5 \cdot N \cdot D \text {, quadratic } \\
\text { migration model }\end{array}$ \\
\hline 3 & SRPSO & $N=40, w=1.05 \sim 0.5, c_{1}=c_{2}=1.49445$ \\
\hline 4 & SLPSO & $N=100+$ floor $(D / 10)$, social influence factor $\varepsilon=0.0001 D$ \\
\hline 5 & EPSO & $N_{1}=15, N_{2}=25$, strategy number $n s=5$, learning period $L R=50$ \\
\hline 7 & $\mathrm{ABC}$ & $N=50$, limit $=N \times D$ \\
\hline 8 & GABC & $N=50$, limit $=N \times D, C=1.5$ \\
\hline 9 & qABC & $N=50$, limit $=N \times D$, neighborhood radius $r=1$ \\
\hline 10 & ABCVSS & $N=50$, limit $=N \times D$, number of search equations $N E=5$ \\
\hline 11 & DFSABC & $N=50$, limit $=N \times D$, elite solution proportion $p=0.1, r=1 / p$ \\
\hline
\end{tabular}

\subsection{Parameter tuning}

In BFL-PSO, there is a parameter limit in the scout learning phase which needs to be carefully tuned. The candidate values for limit are set as limit $=K \times N \times D$, where $K=5,2,1,0.5$, $0.2,0.1$ and $0.05, N$ is the population size, and $D$ is the problem dimension.

Table 3 presents the of Friedman ranks of BFL-PSO with different limit values on CEC2014 functions. The mean function error values are provides in Table A1 of Appendix 2.

From Table 3, the limit values range from $0.1 \times N \times D$ to $0.5 \times N \times D$ provide more favorable performance. According to the final ranks, BFL-PSO with limit $=0.5 \times N \times D$ exhibits the overall best performance on the CEC2014 functions.

Table 3: Friedman ranks of BFL-PSO with different limit values

\begin{tabular}{cccccccc}
\multicolumn{7}{c}{ Table 3: Friedman ranks of BFL-PSO with different limit values } \\
\hline limit & $5 \times N \times D$ & $2 \times N \times D$ & $N \times D$ & $0.5 \times N \times D$ & $0.2 \times N \times D$ & $0.1 \times N \times D$ & $0.05 \times N \times D$ \\
\hline Friedman rank & 4.82 & 3.92 & 4.23 & 3.25 & 3.48 & 3.88 & 4.42 \\
Final rank & 7 & 4 & 5 & 1 & 2 & 3 & 6 \\
\hline
\end{tabular}

\subsection{Effectiveness of new search phases introduced in BFL-PSO}

BFL-PSO introduces two new search phases, i.e., onlooker learning and scout learning, to traditional one-phase-based PSO. To investigate the effectiveness of both new search phases, BFL-PSO is compared with its two partial versions: (1) the first one is a partial BFL-PSO with only employed and onlooker learning phases, i.e., BFL-PSO without scout learning phase (denoted as BFL-PSO-woSC); (2) The second one is BFL-PSO with only employed and scout learning phases, i.e., BFL-PSO without onlooker learning phase (denoted as BFL-PSO-woON).

Table 4 presents the comparison results of BFL-PSO and its two partial versions. 
From Table 4, BLF-PSO performs significantly better, similar and worse than BFL-PSOwoSC on 10,17, and 3 functions, respectively. Moreover, BFL-PSO achieves much better results than BFL-PSO-woSC on the simple multimodal and composite functions. These observations indicate the effectiveness of scout learning in BFL-PSO in contrast to BFL-PSO-woSC without scout learning.

BLF-PSO performs significantly better, similar and worse than BFL-PSO-woON on 15, 13, and 2 functions, respectively. Moreover, BFL-PSO achieves much better results than BFLPSO-woON on the simple multimodal and composite functions. These observations indicate the effectiveness of onlooker learning in BFL-PSO in contrast to BFL-PSO-woON without onlooker learning.

Fig.2 plots the convergence graphs of BFL-PSO and BFL-PSO-woSC without scout learning on functions F08, F10, F26 and F27. The scout learning in BFL-PSO re-initializes the positions and velocities of those exhausted particles, which brings new swarm diversity to prevent stagnation. Therefore, BFL-PSO exhibits exploration search in comparison with BFL-PSO-woSC, and achieves more accurate solutions on these functions.

Fig.3 plots the convergence graphs of BFL-PSO and BFL-PSO-woON without onlooker learning on functions F03, F07, F27 and F30. The onlooker learning in BFL-PSO selects those particles with better fitness to perform strengthened search. Therefore, BFL-PSO exhibits exploitation search in comparison with BFL-PSO-woON, which improves the solution quality on these functions.

In summary, based on these analyses, it can be said that both onlooker learning and scout learning phases play important roles in the search process of BLF-PSO. The onlooker learning can enhance the exploitation, while the scout learning can enhance the exploration. Both onlooker and scout learning are important for the performance enhancement of BFL-PSO. 
Table 4: Comparison results of BFL-PSO with its two partial versions

\begin{tabular}{|c|c|c|c|c|c|c|c|c|}
\hline \multicolumn{3}{|c|}{ BFL-PSO } & \multicolumn{2}{|c|}{ BFL-PSO-woScout } & \multicolumn{4}{|c|}{ BFL-PSO-woOnlooker } \\
\hline & Mean & SD & Mean & $\mathrm{SD}$ & & Mean & SD & \\
\hline F01 & $3.26 \mathrm{E}+06$ & $(1.48 \mathrm{E}+06)$ & $2.94 \mathrm{E}+06$ & $(2.04 \mathrm{E}+06)$ & $=$ & $3.81 \mathrm{E}+06$ & $(1.88 \mathrm{E}+06)$ & $=$ \\
\hline F02 & $9.09 \mathrm{E}+03$ & $(6.24 \mathrm{E}+03)$ & $8.37 \mathrm{E}+03$ & $(7.48 \mathrm{E}+03)$ & $=$ & $9.18 \mathrm{E}+03$ & $(7.05 \mathrm{E}+03)$ & $=$ \\
\hline F03 & $1.50 \mathrm{E}+01$ & $(3.67 \mathrm{E}+01)$ & $4.02 \mathrm{E}+01$ & $(1.31 \mathrm{E}+02)$ & $=$ & $2.31 \mathrm{E}+02$ & $(5.65 \mathrm{E}+02)$ & + \\
\hline F04 & $8.79 \mathrm{E}+01$ & $(2.48 \mathrm{E}+01)$ & $9.14 \mathrm{E}+01$ & $(2.47 \mathrm{E}+01)$ & $=$ & $9.90 \mathrm{E}+01$ & $(2.63 \mathrm{E}+01)$ & + \\
\hline F05 & $2.03 \mathrm{E}+01$ & $(5.25 \mathrm{E}-02)$ & $2.03 \mathrm{E}+01$ & $(4.64 \mathrm{E}-02)$ & - & $2.03 \mathrm{E}+01$ & $(5.40 \mathrm{E}-02)$ & - \\
\hline F06 & $1.38 \mathrm{E}+00$ & $(8.75 \mathrm{E}-01)$ & $1.59 \mathrm{E}+00$ & $(1.78 \mathrm{E}+00)$ & $=$ & $2.04 \mathrm{E}+00$ & $(9.26 \mathrm{E}-01)$ & + \\
\hline F07 & $0.00 \mathrm{E}+00$ & $(0.00 \mathrm{E}+00)$ & $1.45 \mathrm{E}-04$ & $(1.04 \mathrm{E}-03)$ & $=$ & $4.35 \mathrm{E}-04$ & $(1.76 \mathrm{E}-03)$ & $=$ \\
\hline F08 & 3.91E-01 & $(5.29 \mathrm{E}-01)$ & $1.40 \mathrm{E}+00$ & $(1.09 \mathrm{E}+00)$ & + & 8.39E-01 & $(8.05 \mathrm{E}-01)$ & + \\
\hline F09 & $1.69 \mathrm{E}+01$ & $(3.12 \mathrm{E}+00)$ & $2.41 \mathrm{E}+01$ & $(3.99 \mathrm{E}+00)$ & + & $1.90 \mathrm{E}+01$ & $(4.09 \mathrm{E}+00)$ & + \\
\hline F10 & $1.42 \mathrm{E}+01$ & $(1.63 \mathrm{E}+01)$ & $2.45 \mathrm{E}+01$ & $(2.81 \mathrm{E}+01)$ & + & $2.02 \mathrm{E}+01$ & $(2.84 \mathrm{E}+01)$ & $=$ \\
\hline F11 & $1.29 \mathrm{E}+03$ & $(2.68 \mathrm{E}+02)$ & $1.56 \mathrm{E}+03$ & $(2.88 \mathrm{E}+02)$ & + & $1.42 \mathrm{E}+03$ & $(3.59 \mathrm{E}+02)$ & + \\
\hline $\mathrm{F} 12$ & $3.45 \mathrm{E}-01$ & $(7.05 \mathrm{E}-02)$ & $3.10 \mathrm{E}-01$ & $(5.25 \mathrm{E}-02)$ & - & 2.87E-01 & $(5.22 \mathrm{E}-02)$ & - \\
\hline F13 & 8.57E-02 & $(1.41 \mathrm{E}-02)$ & $1.60 \mathrm{E}-01$ & $(2.60 \mathrm{E}-02)$ & + & $8.60 \mathrm{E}-02$ & $(1.94 \mathrm{E}-02)$ & $=$ \\
\hline F14 & $2.11 \mathrm{E}-01$ & $(3.96 \mathrm{E}-02)$ & $2.25 \mathrm{E}-01$ & (3.07E-02) & + & 2.02E-01 & $(3.83 \mathrm{E}-02)$ & $=$ \\
\hline F15 & $3.54 \mathrm{E}+00$ & (4.37E-01) & $4.06 \mathrm{E}+00$ & (5.32E-01) & + & $3.48 \mathrm{E}+00$ & (4.39E-01) & $=$ \\
\hline F16 & $7.34 \mathrm{E}+00$ & $(7.15 \mathrm{E}-01)$ & $8.80 \mathrm{E}+00$ & (6.02E-01) & + & $7.66 \mathrm{E}+00$ & (5.48E-01) & + \\
\hline F17 & $3.59 \mathrm{E}+05$ & $(2.31 \mathrm{E}+05)$ & $3.15 \mathrm{E}+05$ & $(1.70 \mathrm{E}+05)$ & $=$ & $4.27 \mathrm{E}+05$ & $(2.88 \mathrm{E}+05)$ & $=$ \\
\hline F18 & $1.04 \mathrm{E}+03$ & $(1.54 \mathrm{E}+03)$ & $8.75 \mathrm{E}+02$ & $(1.29 \mathrm{E}+03)$ & $=$ & $1.28 \mathrm{E}+03$ & $(1.77 \mathrm{E}+03)$ & $=$ \\
\hline F19 & $4.56 \mathrm{E}+00$ & $(9.88 \mathrm{E}-01)$ & $4.44 \mathrm{E}+00$ & $(1.08 \mathrm{E}+00)$ & $=$ & $5.02 \mathrm{E}+00$ & $(1.20 \mathrm{E}+00)$ & $=$ \\
\hline F20 & $1.06 \mathrm{E}+03$ & $(1.08 \mathrm{E}+03)$ & $5.58 \mathrm{E}+02$ & $(6.98 \mathrm{E}+02)$ & - & $9.51 \mathrm{E}+02$ & $(1.25 \mathrm{E}+03)$ & $=$ \\
\hline F21 & $6.21 \mathrm{E}+04$ & $(5.14 \mathrm{E}+04)$ & $4.73 \mathrm{E}+04$ & $(4.05 \mathrm{E}+04)$ & $=$ & $6.13 \mathrm{E}+04$ & $(5.07 \mathrm{E}+04)$ & $=$ \\
\hline F22 & $9.56 \mathrm{E}+01$ & $(6.23 \mathrm{E}+01)$ & $1.18 \mathrm{E}+02$ & $(7.40 \mathrm{E}+01)$ & $=$ & $1.08 \mathrm{E}+02$ & $(6.23 \mathrm{E}+01)$ & $=$ \\
\hline F23 & $3.15 \mathrm{E}+02$ & $(9.53 \mathrm{E}-10)$ & $3.15 \mathrm{E}+02$ & $(8.15 \mathrm{E}-11)$ & $=$ & $3.15 \mathrm{E}+02$ & $(5.10 \mathrm{E}-06)$ & + \\
\hline F24 & $2.24 \mathrm{E}+02$ & $(6.82 \mathrm{E}-01)$ & $2.24 \mathrm{E}+02$ & $(1.10 \mathrm{E}+00)$ & $=$ & $2.25 \mathrm{E}+02$ & $(1.42 \mathrm{E}+00)$ & + \\
\hline F25 & $2.05 \mathrm{E}+02$ & $(4.75 \mathrm{E}-01)$ & $2.05 \mathrm{E}+02$ & $(7.04 \mathrm{E}-01)$ & $=$ & $2.05 \mathrm{E}+02$ & (6.36E-01) & + \\
\hline F26 & $1.00 \mathrm{E}+02$ & $(1.99 \mathrm{E}-02)$ & $1.02 \mathrm{E}+02$ & $(1.40 \mathrm{E}+01)$ & + & $1.00 \mathrm{E}+02$ & (1.02E-01) & + \\
\hline F27 & $3.52 \mathrm{E}+02$ & $(4.46 \mathrm{E}+01)$ & $3.73 \mathrm{E}+02$ & $(4.33 \mathrm{E}+01)$ & + & $3.74 \mathrm{E}+02$ & $(3.99 \mathrm{E}+01)$ & + \\
\hline F28 & $8.07 \mathrm{E}+02$ & $(3.58 \mathrm{E}+01)$ & $8.03 \mathrm{E}+02$ & $(3.42 \mathrm{E}+01)$ & $=$ & $8.19 \mathrm{E}+02$ & $(4.30 \mathrm{E}+01)$ & + \\
\hline F 29 & $1.29 \mathrm{E}+03$ & $(2.78 \mathrm{E}+02)$ & $1.21 \mathrm{E}+03$ & $(3.35 \mathrm{E}+02)$ & $=$ & $1.48 \mathrm{E}+03$ & $(3.39 \mathrm{E}+02)$ & + \\
\hline F30 & $2.19 \mathrm{E}+03$ & $(6.20 \mathrm{E}+02)$ & $2.18 \mathrm{E}+03$ & $(6.69 \mathrm{E}+02)$ & $=$ & $2.91 \mathrm{E}+03$ & $(8.58 \mathrm{E}+02)$ & + \\
\hline$\overline{\mathrm{F} 01 \sim \mathrm{F} 03}$ & $+/=/-$ & & $0-3-0$ & & & $1-2-0$ & & \\
\hline $\mathrm{F} 04 \sim \mathrm{F} 16$ & $+/=/-$ & & $8-3-2$ & & & $6-5-2$ & & \\
\hline $\mathrm{F} 17 \sim \mathrm{F} 22$ & $+/=/-$ & & $0-5-1$ & & & $0-6-0$ & & \\
\hline F $23 \sim F 30$ & $+1=/-$ & & $2-6-0$ & & & $8-0-0$ & & \\
\hline Total & & & $10-17-3$ & & & $15-13-2$ & & \\
\hline
\end{tabular}

The symbols,$+=$ and - mean that BFL-PSO is significantly superior, similar or inferior to its competitor, respectively, according to the Wilcoxon rank sum test at $\alpha=0.05$ significance level.

The best results in terms of mean function error are highlighted in bold. 

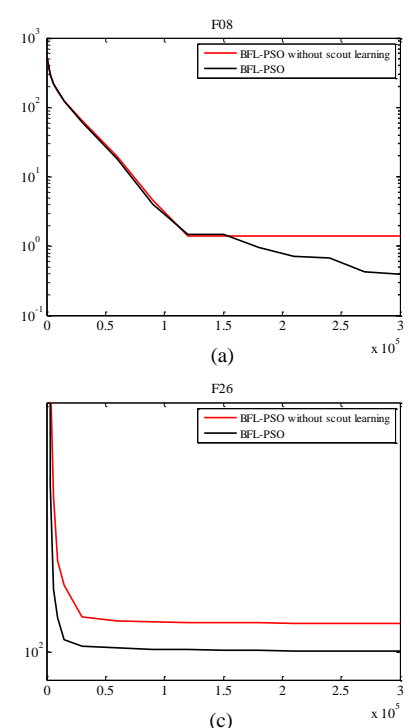
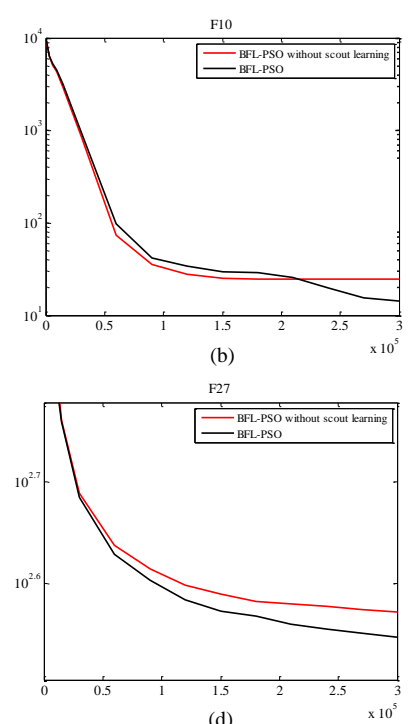

Figure 2: Convergence graphs of BFL-PSO and BFL-PSO without scout learning.
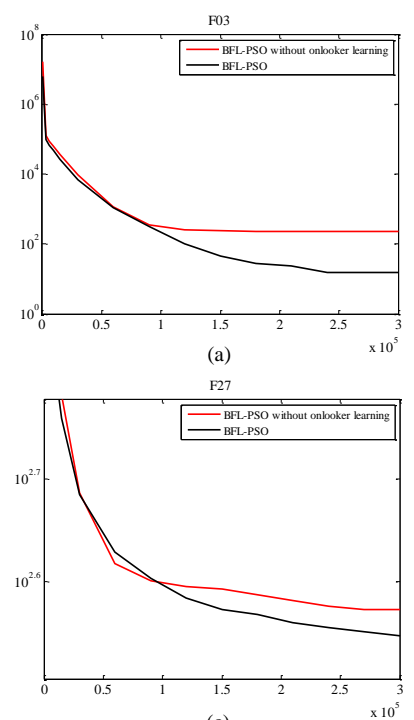
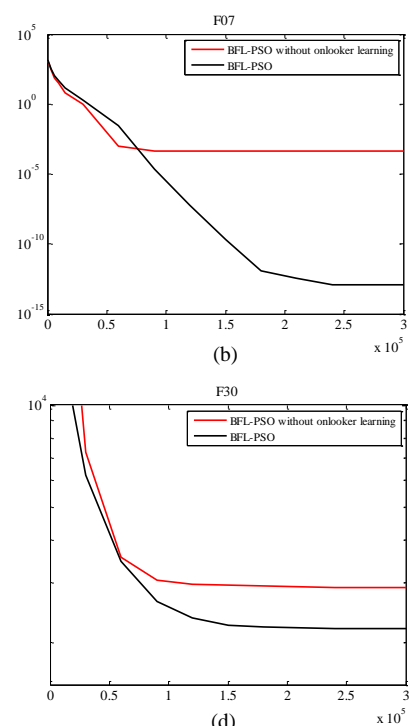

Figure 3: Convergence graphs of BFL-PSO and BFL-PSO without onlooker learning. 


\subsection{BFL-PSO vs. five state-of-the-art PSO}

The proposed BFL-PSO is compared with five state-of-the-art PSO algorithms, i.e., CLPSO

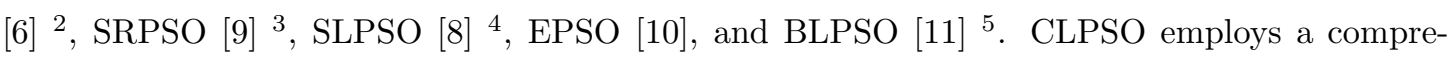
hensive learning strategy where each particle learns from all particles' personal best positions [6]. SRPSO uses a self-regulating inertia weight and self-perception global search direction [9]. SLPSO introduces a social learning mechanism where each particle learns from different better particles in different dimension [8]. EPSO employs an ensemble of five different PSO updating strategies [III]. BLPSO uses a biogeography-based learning strategy where each particle updates itself through the biogeography-based migration [II]. It is worth noting that BLPSO is the same as BFL-PSO when both onlooker learning and scout learning phases in BFL-PSO are removed.

Table 5 presents the comparison results of BFL-PSO and the five PSO algorithms.

For the unimodal functions, EPSO achieves the best results on F01 and F03. CLPSO achieves the best results on F02. The performance of BFL-PSO is not satisfactory.

For the simple multimodal functions, BFL-PSO achieves the best results on 6 functions (F07, F09 and F13 F16). CLPSO, SLPSO and BLPSO achieve the best results on 2 functions, respectively. EPSO achieves the best results on 1 function.

For the hybrid functions, EPSO achieves the best results on 3 functions. BFL-PSO, CLPSO and BLPSO achieve the best results on 1 function, respectively.

For the composite functions, BFL-PSO achieves the best results on 4 functions (F25 F28). EPSO achieves the best results on 3 functions (F23, F29 and F30). SRPSO, SLPSO and BLPSO achieve the best results on 1 function, respectively.

Considering all the functions, according to the Wilcoxon rank sum test in the last row, BFLPSO performs significantly better than CLPSO, SRPSO, SLPSO, EPSO and BLPSO on 21, 21, 18, 17 and 13 functions, respectively. By contrast, BFL-PSO performs worse than them on 6, 5, 6,11 and 3 functions, respectively.

The above comparisons show that BLF-PSO achieves the overall best results on CEC2014 functions in comparison with the five PSO algorithms. Although BLF-PSO doesn't seem very efficient for the unimodal functions, it achieves very good performance for the simple multimodal and composite functions. For hybrid functions, the performance of BFL-PSO is worse than

\footnotetext{
${ }^{2}$ The source codes of CLPSO and EPSO can be download from https://www.ntu.edu.sg/home/EPNSugan/.

${ }^{3}$ The source code of SRPSO is provided by Dr. M.R. Tanweer.

${ }^{4}$ The source code of SLPSO can be download from https://github.com/ranchengcn/.

${ }^{5}$ The source code of BLPSO can be download from https://github.com/chenxu796/BLPSO.
} 
EPSO, while better than other four PSO algorithms. These comparisons indicates BFL-PSO has potential in addressing problems with complex landscapes compared with these PSO algorithms.

\subsection{BFL-PSO vs. five well-established $A B C$}

The proposed BFL-PSO is further compared with five well-established ABC algorithms, i.e., basic ABC [46] ${ }^{\mathbf{1}}$, GABC [47], qABC [48], ABCVSS [49], and DFSABC [50]. ABC uses three bee search phases and one-variable-based updating search equation to find good solutions [46]. GABC introduces the global best solution into the search equation to improve the exploitation [47]. qABC searches around the best solution among neighbors in the onlooker bee phase [48]. ABCVSS employs five different search strategies to update the positions of food sources [49]. DFSABC applies a depth-first search framework and two elite-guided search equations to ABC [50].

Table 6 presents the comparison results of BFL-PSO and the five ABC algorithms.

For the unimodal functions, BFL-PSO achieves the best result on F03. qABC and DFSABC achieve the best results on F01 and F02, respectively.

For the simple multimodal functions, BFL-PSO achieves the best results on 7 functions (F06, F07, F9, F11, F13, F15 and F16). qABC achieves the best results on 4 functions (F04, F05, F08 and F12). ABC, ABCVSS, GABC and DFSABC achieve the best results on 2, 2, 1 and 1 functions, respectively.

For the hybrid functions, BFL-PSO achieves the best results on 5 functions (F17, F19 F22). ABCVSS achieves the best results on 1 function.

For the composite functions, BFL-PSO achieves the best results on 6 functions (F23, F25 F28 and F30). qABC and ABCVSS achieve the best results on 1 function, respectively.

Considering all the functions, according to the Wilcoxon rank sum test in the last row, BFLPSO is superior to ABC, GABC, qABC, ABCVSS, and DFSABC on 21, 22, 19, 23 and 21 functions respectively. By contrast, BFL-PSO is inferior to ABC, GABC, qABC, ABCVSS, and DFSABC on 8, 8, 7, 6 and 9 functions, respectively.

The above comparisons show that BFL-PSO performs significantly better than the five ABC algorithms on most of CE2014 functions, especially on the hybrid and composite functions.

\footnotetext{
${ }^{6}$ The source code of ABC can be download from https://abc.erciyes.edu.tr/software.htm.
} 
Table 5: Comparison results of BFL-PSO with five state-of-the-art PSO algorithms on CEC 2014 benchmark functions

\begin{tabular}{|c|c|c|c|c|c|c|c|}
\hline & BFL-PSO & CLPSO & SRPSO & SLPSO & EPSO & BLPSO & \\
\hline \multirow[t]{2}{*}{ F01 } & $3.26 \mathrm{E}+06$ & $8.91 \mathrm{E}+06$ & $1.60 \mathrm{E}+06$ & $3.86 \mathrm{E}+05$ & $1.53 \mathrm{E}+05$ & $3.56 \mathrm{E}+06$ & \\
\hline & $(1.48 \mathrm{E}+06)$ & $(2.90 \mathrm{E}+06)$ & $+(1.60 \mathrm{E}+06)$ & $(2.60 \mathrm{E}+05)$ & $(1.17 \mathrm{E}+05)$ & $(1.68 \mathrm{E}+06)$ & $=$ \\
\hline \multirow[t]{2}{*}{ F02 } & $9.09 \mathrm{E}+03$ & $6.95 \mathrm{E}+01$ & $3.00 \mathrm{E}+03$ & $1.09 \mathrm{E}+04$ & $1.01 \mathrm{E}+02$ & $9.32 \mathrm{E}+03$ & \\
\hline & $(6.24 \mathrm{E}+03)$ & $(1.26 \mathrm{E}+02)$ & $(3.54 \mathrm{E}+03)$ & $(9.31 \mathrm{E}+03)$ & $(2.23 \mathrm{E}+02)$ & $(7.04 \mathrm{E}+03)$ & $=$ \\
\hline \multirow[t]{2}{*}{ F03 } & $1.50 \mathrm{E}+01$ & $1.43 \mathrm{E}+02$ & $5.25 \mathrm{E}+01$ & $6.93 \mathrm{E}+03$ & 6.36E-01 & $9.42 \mathrm{E}+01$ & \\
\hline & $(3.67 \mathrm{E}+01)$ & $(1.56 \mathrm{E}+02)$ & $+(5.61 \mathrm{E}+01)$ & $(4.99 \mathrm{E}+03)$ & $(9.13 \mathrm{E}-01)$ & $(2.42 \mathrm{E}+02)$ & $=$ \\
\hline \multirow[t]{2}{*}{ F04 } & $8.79 \mathrm{E}+01$ & $7.06 \mathrm{E}+01$ & $1.09 \mathrm{E}+02$ & $4.26 \mathrm{E}+01$ & $3.80 \mathrm{E}+00$ & $8.93 \mathrm{E}+01$ & \\
\hline & $(2.48 \mathrm{E}+01)$ & $(1.95 \mathrm{E}+01)$ & $=(3.47 \mathrm{E}+01)$ & $+(3.58 \mathrm{E}+01)$ & $(1.41 \mathrm{E}+01)$ & $(2.44 \mathrm{E}+01)$ & $=$ \\
\hline \multirow[t]{2}{*}{ F05 } & $2.03 \mathrm{E}+01$ & $2.03 \mathrm{E}+01$ & $2.09 \mathrm{E}+01$ & $2.09 \mathrm{E}+01$ & $2.05 \mathrm{E}+01$ & $2.03 \mathrm{E}+01$ & \\
\hline & $(5.25 \mathrm{E}-02)$ & $(3.95 \mathrm{E}-02)$ & $(6.50 \mathrm{E}-02)$ & $+\quad(5.02 \mathrm{E}-02)$ & $+\quad(6.15 \mathrm{E}-02)$ & $+\quad(4.12 \mathrm{E}-02)$ & - \\
\hline \multirow[t]{2}{*}{ F06 } & $1.38 \mathrm{E}+00$ & $1.30 \mathrm{E}+01$ & $2.63 \mathrm{E}+00$ & $8.43 \mathrm{E}-01$ & $6.23 \mathrm{E}+00$ & $1.34 \mathrm{E}+00$ & \\
\hline & $(8.75 \mathrm{E}-01)$ & $(1.42 \mathrm{E}+00)$ & $(2.19 \mathrm{E}+00)$ & $(1.08 \mathrm{E}+00)$ & $(2.64 \mathrm{E}+00)$ & $(1.43 \mathrm{E}+00)$ & $=$ \\
\hline \multirow[t]{2}{*}{ F07 } & $0.00 \mathrm{E}+00$ & $6.32 \mathrm{E}-05$ & 1.03E-02 & $5.32 \mathrm{E}-04$ & $3.43 \mathrm{E}-03$ & 1.93E-04 & \\
\hline & $(0.00 \mathrm{E}+00)$ & $(1.16 \mathrm{E}-04)$ & $(1.05 \mathrm{E}-02)$ & $(2.17 \mathrm{E}-03)$ & $(5.00 \mathrm{E}-03)$ & $(1.38 \mathrm{E}-03)$ & $=$ \\
\hline \multirow[t]{2}{*}{ F08 } & $3.91 \mathrm{E}-01$ & $0.00 E+00$ & $3.04 \mathrm{E}+01$ & $1.62 \mathrm{E}+01$ & $5.85 \mathrm{E}-02$ & $1.23 \mathrm{E}+00$ & \\
\hline & $(5.29 \mathrm{E}-01)$ & $(0.00 \mathrm{E}+00)$ & $(8.18 \mathrm{E}+00)$ & $(4.47 \mathrm{E}+00)$ & $(2.36 \mathrm{E}-01)$ & $(1.33 \mathrm{E}+00)$ & + \\
\hline \multirow[t]{2}{*}{ F09 } & $1.69 \mathrm{E}+01$ & $5.42 \mathrm{E}+01$ & $4.02 \mathrm{E}+01$ & $1.93 \mathrm{E}+01$ & $4.42 \mathrm{E}+01$ & $2.49 \mathrm{E}+01$ & \\
\hline & $(3.12 \mathrm{E}+00)$ & $(6.67 \mathrm{E}+00)$ & $+(1.22 \mathrm{E}+01)$ & $(1.32 \mathrm{E}+01)$ & $(1.21 \mathrm{E}+01)$ & $+(4.75 \mathrm{E}+00)$ & + \\
\hline \multirow[t]{2}{*}{ F10 } & $1.42 \mathrm{E}+01$ & 1.49E-01 & $6.94 \mathrm{E}+02$ & $4.23 \mathrm{E}+02$ & $1.75 \mathrm{E}+01$ & $3.21 \mathrm{E}+01$ & \\
\hline & $(1.63 \mathrm{E}+01)$ & (3.43E-02) & $-\quad(2.61 \mathrm{E}+02)$ & $+(2.10 \mathrm{E}+02)$ & $+(1.78 \mathrm{E}+01)$ & $+(4.02 \mathrm{E}+01)$ & + \\
\hline \multirow[t]{2}{*}{ F11 } & $E+03$ & $2.23 \mathrm{E}+03$ & $2.00 \mathrm{E}+03$ & $8.85 \mathrm{E}+02$ & $1.94 \mathrm{E}+03$ & $1.75 \mathrm{E}+03$ & \\
\hline & $(2.68 \mathrm{E}+02)$ & $(2.95 \mathrm{E}+02)$ & $(6.15 \mathrm{E}+02)$ & $(3.91 \mathrm{E}+02)$ & $(4.31 \mathrm{E}+02)$ & $(2.78 \mathrm{E}+02)$ & + \\
\hline \multirow[t]{2}{*}{$\mathrm{F} 12$} & $3.45 \mathrm{E}-01$ & $3.44 \mathrm{E}$ & $2.38 \mathrm{E}+00$ & $2.19 \mathrm{E}+00$ & 4.99E-01 & 3.00E-01 & \\
\hline & (7.05E-02) & $(5.15 \mathrm{H}$ & $(3.93 \mathrm{H}$ & $(5.61 \mathrm{E}$ & $(1.03 \mathrm{E}-01)$ & $(6.51 \mathrm{~F}$ & - \\
\hline F13 & $8.57 \mathrm{E}-02$ & $2.94 \mathrm{E}-01$ & $2.52 \mathrm{E}-01$ & $1.72 \mathrm{E}-01$ & $2.75 \mathrm{E}-01$ & $1.60 \mathrm{E}-01$ & \\
\hline & $(1.41 \mathrm{E}-02)$ & $(4.14 \mathrm{E}-02)$ & $(4.52 \mathrm{E}-02)$ & $(3.65 \mathrm{E}-02)$ & $(4.06 \mathrm{E}-02)$ & $(2.68 \mathrm{E}-02)$ & + \\
\hline F14 & $2.11 \mathrm{E}-01$ & $2.66 \mathrm{E}-01$ & $2.21 \mathrm{E}-01$ & $4.09 \mathrm{E}$ & $2.39 \mathrm{E}-01$ & $2.27 \mathrm{E}-01$ & \\
\hline & $(3.96 \mathrm{E}-02)$ & $(2.98 \mathrm{E}-02)$ & (3.03E-02) & $(7.70 \mathrm{E}-02)$ & $(3.80 \mathrm{E}-02)$ & $(3.51 \mathrm{E}-02)$ & + \\
\hline F15 & $3.54 \mathrm{E}+00$ & $8.14 \mathrm{E}+00$ & $8.41 \mathrm{E}+00$ & $6.11 \mathrm{E}+00$ & $5.82 \mathrm{E}+00$ & $4.08 \mathrm{E}+00$ & \\
\hline & $(4.37 \mathrm{E}-01)$ & $(9.27 \mathrm{E}-01)$ & $+(4.81 \mathrm{E}+00)$ & $(4.72 \mathrm{E}+00)$ & $(3.80 \mathrm{E}+00)$ & $(6.38 \mathrm{E}-01)$ & + \\
\hline F16 & $7.34 \mathrm{E}+00$ & $1.02 \mathrm{E}+01$ & $1.11 \mathrm{E}+01$ & $1.20 \mathrm{E}+01$ & $1.02 \mathrm{E}+01$ & $8.71 \mathrm{E}+00$ & \\
\hline & $(7.15 \mathrm{E}-01)$ & $(3.63 \mathrm{E}-01)$ & $(4.98 \mathrm{E}-01)$ & $(2.97 \mathrm{E}-01)$ & (6.93E-01) & (5.50E-01) & + \\
\hline F17 & $3.59 \mathrm{E}+05$ & $9.24 \mathrm{E}+05$ & $1.90 \mathrm{E}+05$ & $9.19 \mathrm{E}+04$ & $4.15 \mathrm{E}+04$ & $4.92 \mathrm{E}+05$ & \\
\hline & $(2.31 \mathrm{E}+05)$ & $(5.07 \mathrm{E}+05)$ & $+(1.18 \mathrm{E}+05)$ & $(6.03 \mathrm{H}$ & $(4.35 \mathrm{E}+04)$ & $(2.71 \mathrm{E}+05)$ & + \\
\hline F18 & $1.04 \mathrm{E}+03$ & $8.39 \mathrm{E}+01$ & 3.7 & 2.59 & $2.73 \mathrm{E}+02$ & +03 & \\
\hline & $(1.54 \mathrm{E}+03)$ & $(3.36 \mathrm{E}$ & $+03)$ & $(3.65 \mathrm{E}$ & $(2.01 \mathrm{E}+02)$ & $(1.40 \mathrm{E}+03)$ & $=$ \\
\hline F19 & $4.56 \mathrm{E}+00$ & $7.68 \mathrm{E}$ & +00 & $8.05 \mathrm{E}+00$ & $6.07 \mathrm{E}+00$ & $4.43 E+00$ & \\
\hline & $-01)$ & -01) & $(1.53 \mathrm{E}+00)$ & $(8.231$ & $(1.28 \mathrm{E}+0$ & $\mathrm{E}-01)$ & $=$ \\
\hline F20 & $1.06 \mathrm{E}+03$ & $2.88 \mathrm{E}+03$ & $2.77 \mathrm{E}+02$ & $2.18 \mathrm{E}+04$ & $2.54 \mathrm{E}+02$ & $4.62 \mathrm{E}+02$ & \\
\hline & $(1.08 \mathrm{E}+03)$ & $(1.90 \mathrm{E}+03)$ & $+(7.71 \mathrm{E}+01)$ & $(1.30 \mathrm{E}+04)$ & $(1.20 \mathrm{E}+02)$ & $(5.93 \mathrm{E}+02)$ & - \\
\hline F21 & $6.21 \mathrm{E}+04$ & $9.42 \mathrm{E}+04$ & $6.42 \mathrm{E}+04$ & $9.48 \mathrm{E}+04$ & $2.85 \mathrm{E}+04$ & $8.52 \mathrm{E}+04$ & \\
\hline & $(5.14 \mathrm{E}+04)$ & $(5.62 \mathrm{E}+04)$ & $+(4.40 \mathrm{E}+04)$ & $(7.65 \mathrm{E}+04)$ & $(3.86 \mathrm{E}+04)$ & $(9.09 \mathrm{E}+04)$ & $=$ \\
\hline $\mathrm{F} 22$ & $9.56 \mathrm{E}+01$ & $2.04 \mathrm{E}+02$ & $2.72 \mathrm{E}+02$ & $1.61 \mathrm{E}+02$ & $2.22 \mathrm{E}+02$ & $9.91 \mathrm{E}+01$ & \\
\hline & $\mathrm{E}+01)$ & $(5.69 \mathrm{E}+01)$ & $+(9.44 \mathrm{E}+01)$ & $+(8.89 \mathrm{E}+01)$ & $+(8.94 \mathrm{E}+01)$ & $+(6.81 \mathrm{E}+01)$ & $=$ \\
\hline F23 & $3.15 \mathrm{E}+02$ & $3.15 \mathrm{E}+02$ & $3.15 \mathrm{E}+02$ & $3.15 \mathrm{E}+02$ & $3.15 \mathrm{E}+02$ & $3.15 \mathrm{E}+02$ & \\
\hline & E-10) & (6.13E-05) & $(6.26 \mathrm{E}-02)$ & $-12)$ & $(1.50 \mathrm{E}-12)$ & $(2.01 \mathrm{E}-10)$ & $=$ \\
\hline $\mathrm{F} 24$ & $2.24 \mathrm{E}+02$ & $2.24 \mathrm{E}+02$ & $2.06 \mathrm{E}+02$ & $2.30 \mathrm{E}$ & $2.24 \mathrm{E}+02$ & $2.24 \mathrm{E}+02$ & \\
\hline & 01) & 00) & 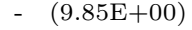 & $(6.691)$ & $(2.58 \mathrm{E}-$ & -01) & $=$ \\
\hline F 25 & $2.05 \mathrm{E}+02$ & $2.08 \mathrm{E}$ & $2.05 \mathrm{E}+02$ & $2.05 \mathrm{E}+02$ & $2.06 \mathrm{E}+02$ & $2.05 \mathrm{E}+02$ & \\
\hline & & & $(9.79 \mathrm{E}-01)$ & $(1.39 \mathrm{E}+00)$ & & (6.37E-01) & + \\
\hline F26 & $1.00 \mathrm{E}+02$ & $1.00 \mathrm{E}+02$ & $1.36 \mathrm{E}+02$ & $1.12 \mathrm{E}+02$ & $1.08 \mathrm{E}+02$ & $1.00 \mathrm{E}+02$ & \\
\hline & $(1.99 \mathrm{E}-02)$ & $(7.01 \mathrm{E}-02)$ & $+(4.77 \mathrm{E}+01)$ & $(3.25 \mathrm{E}+01)$ & $(2.71 \mathrm{E}+01)$ & $(2.80 \mathrm{E}-02)$ & + \\
\hline F27 & $3.52 \mathrm{E}+02$ & $4.14 \mathrm{E}+02$ & $4.38 \mathrm{E}+02$ & $3.75 \mathrm{E}+02$ & $4.02 \mathrm{E}+02$ & $3.57 \mathrm{E}+02$ & \\
\hline & $(4.46 \mathrm{E}+01)$ & $(5.09 \mathrm{E}+00)$ & $(7.65 \mathrm{E}+01)$ & $(6.14 \mathrm{E}+01)$ & (8.17E-01) & $+(4.62 \mathrm{E}+01)$ & $=$ \\
\hline F 28 & $8.07 \mathrm{E}+02$ & $9.05 \mathrm{E}+02$ & $9.87 \mathrm{E}+02$ & $8.87 \mathrm{E}+02$ & $9.35 \mathrm{E}+02$ & $8.17 \mathrm{E}+02$ & \\
\hline & $(3.58 \mathrm{E}+01)$ & $(3.90 \mathrm{E}+01)$ & $+(2.44 \mathrm{E}+02)$ & $(4.43 \mathrm{E}+01)$ & $+(5.98 \mathrm{E}+01)$ & $+(2.42 \mathrm{E}+01)$ & $=$ \\
\hline F29 & $1.29 \mathrm{E}+03$ & $9.89 \mathrm{E}+02$ & $9.17 \mathrm{E}+05$ & $1.89 \mathrm{E}+03$ & $9.21 \mathrm{E}+02$ & $1.42 \mathrm{E}+03$ & \\
\hline & $(2.78 \mathrm{E}+02)$ & $(1.34 \mathrm{E}+02)$ & $(3.70 \mathrm{E}+06)$ & $(5.77 \mathrm{E}+02)$ & $+(1.14 \mathrm{E}+02)$ & $(3.53 \mathrm{E}+02)$ & + \\
\hline F30 & $2.19 \mathrm{E}+03$ & $3.69 \mathrm{E}+03$ & $2.38 \mathrm{E}+03$ & $3.20 \mathrm{E}+03$ & $1.77 \mathrm{E}+03$ & $2.52 \mathrm{E}+03$ & \\
\hline & $(6.20 \mathrm{E}+02)$ & $(1.02 \mathrm{E}+03)$ & $(8.74 \mathrm{E}+02)$ & $(1.17 \mathrm{E}+03)$ & $(5.07 \mathrm{E}+02)$ & $(7.86 \mathrm{E}+02)$ & + \\
\hline 170 & $+/=/-$ & $2-0-1$ & $1-0-2$ & $1-1-1$ & $0-1-2$ & $0-3-0$ & \\
\hline $4 \sim \mathrm{F} 1$ & $+1=1-$ & $8-3-2$ & $12-1-0$ & $7-3-3$ & $10-1-2$ & $8-3-2$ & \\
\hline $17 \sim \mathrm{F} 22$ & $+1=1-$ & $5-0-1$ & $3-1-2$ & $4-1-1$ & $2-0-4$ & $1-4-1$ & \\
\hline F23 F F30 & $+1=1-$ & $6-0-2$ & $5-2-1$ & $6-1-1$ & $5-0-3$ & $4-4-0$ & \\
\hline Total & & $21-3-6$ & $21-4-5$ & $18-6-6$ & $17-2-11$ & $13-14-3$ & \\
\hline
\end{tabular}

The symbols,$+=$ and - mean that BFL-PSO is significantly superior, similar or inferior to its competitor, respectively, according to the Wilcoxon rank sum test at $\alpha=0.05$ significance level.

The best results in terms of mean function error are highlighted in bold. 
Table 6: Comparison Results of BFL-PSO with four well-established ABC algorithms on CEC 2014 benchmark functions

\begin{tabular}{|c|c|c|c|c|c|c|c|}
\hline & BFL-PSO & $\mathrm{ABC}$ & GABC & qABC & ABCVSS & DFSABC & \\
\hline \multirow[t]{2}{*}{ F01 } & $3.26 \mathrm{E}+06$ & $5.83 \mathrm{E}+06$ & $5.10 \mathrm{E}+06$ & $3.09 \mathrm{E}+06$ & $4.75 \mathrm{E}+06$ & $4.29 \mathrm{E}+06$ & \\
\hline & $(1.48 \mathrm{E}+06)$ & $(2.45 \mathrm{E}+06)$ & $+(2.26 \mathrm{E}+06)$ & $(1.71 \mathrm{E}+06)$ & $(2.17 \mathrm{E}+06)$ & $+(2.30 \mathrm{E}+06)$ & + \\
\hline \multirow[t]{2}{*}{ F02 } & $9.09 \mathrm{E}+03$ & $1.02 \mathrm{E}+02$ & $1.10 \mathrm{E}+02$ & $1.21 \mathrm{E}+02$ & $9.15 \mathrm{E}+01$ & $8.88 \mathrm{E}+02$ & \\
\hline & $(6.24 \mathrm{E}+03)$ & $(1.68 \mathrm{E}+02)$ & $(1.18 \mathrm{E}+02)$ & $(1.31 \mathrm{E}+02)$ & $(1.26 \mathrm{E}+02)$ & $(1.54 \mathrm{E}+03)$ & - \\
\hline \multirow[t]{2}{*}{ F03 } & $1.50 \mathrm{E}+01$ & $7.94 \mathrm{E}+02$ & $5.91 \mathrm{E}+02$ & $6.78 \mathrm{E}+02$ & $5.16 \mathrm{E}+02$ & $8.47 \mathrm{E}+02$ & \\
\hline & $(3.67 \mathrm{E}+01)$ & $(6.65 \mathrm{E}+02)$ & $(5.38 \mathrm{E}+02)$ & $(7.77 \mathrm{E}+02)$ & $(5.10 \mathrm{E}+02)$ & $(8.51 \mathrm{E}+02)$ & + \\
\hline \multirow[t]{2}{*}{ F04 } & $8.79 \mathrm{E}+01$ & $2.47 \mathrm{E}+01$ & $3.37 \mathrm{E}+01$ & $1.32 \mathrm{E}+01$ & $2.01 \mathrm{E}+01$ & $3.58 \mathrm{E}+01$ & \\
\hline & $(2.48 \mathrm{E}+01)$ & $(2.52 \mathrm{E}+01)$ & $(2.89 \mathrm{E}+01)$ & $(2.34 \mathrm{E}+01)$ & $(2.40 \mathrm{E}+01)$ & $(3.85 \mathrm{E}+01)$ & - \\
\hline \multirow[t]{2}{*}{ F05 } & $2.03 \mathrm{E}+01$ & $2.01 \mathrm{E}+01$ & $2.01 \mathrm{E}+01$ & $2.00 E+01$ & $2.01 \mathrm{E}+01$ & $2.01 \mathrm{E}+01$ & \\
\hline & (5.25E-02) & (1.93E-02) & (3.37E-02) & (1.13E-02) & $(2.88 \mathrm{E}-02)$ & $(3.05 \mathrm{E}-02)$ & - \\
\hline \multirow[t]{2}{*}{ F06 } & $1.38 \mathrm{E}+00$ & $1.46 \mathrm{E}+01$ & $1.31 \mathrm{E}+01$ & $1.36 \mathrm{E}+01$ & $1.36 \mathrm{E}+01$ & $1.16 \mathrm{E}+01$ & \\
\hline & $(8.75 \mathrm{E}-01)$ & $(1.60 \mathrm{E}+00)$ & $+(1.26 \mathrm{E}+00)$ & $+(1.63 \mathrm{E}+00)$ & $+(1.39 \mathrm{E}+00)$ & $+(1.42 \mathrm{E}+00)$ & + \\
\hline \multirow[t]{2}{*}{ F07 } & $0.00 \mathrm{E}$ & $1.66 \mathrm{E}-05$ & 7.12E-06 & $2.81 \mathrm{E}-07$ & 2.06E-05 & $1.53 \mathrm{E}-03$ & \\
\hline & $(0.00 \mathrm{E}+00)$ & (3.01E-05) & $(9.21 \mathrm{E}-06)$ & $(3.35 \mathrm{E}-07)$ & $(1.91 \mathrm{E}-05)$ & $(1.09 \mathrm{E}-02)$ & + \\
\hline \multirow[t]{2}{*}{ F08 } & $3.91 \mathrm{E}$ & $0.00 \mathrm{E}+00$ & $0.00 \mathrm{E}+00$ & $0.00 \mathrm{E}+00$ & $0.00 \mathrm{E}+00$ & $0.00 \mathrm{E}+00$ & \\
\hline & (5.29E-01) & $(0.00 \mathrm{E}+00)$ & $(0.00 \mathrm{E}+00)$ & $(0.00 \mathrm{E}+00)$ & $(0.00 \mathrm{E}+00)$ & $(0.00 \mathrm{E}+00)$ & - \\
\hline \multirow[t]{2}{*}{ F09 } & $1.69 \mathrm{E}+01$ & $8.24 \mathrm{E}+01$ & $5.65 \mathrm{E}+01$ & $8.30 \mathrm{E}+01$ & $5.34 \mathrm{E}+01$ & $4.17 \mathrm{E}+01$ & \\
\hline & $(3.12 \mathrm{E}+00)$ & $(1.24 \mathrm{E}+01)$ & $(8.87 \mathrm{E}+00)$ & $(1.41 \mathrm{E}+01)$ & $(8.80 \mathrm{E}+00)$ & $(7.34 \mathrm{E}+00)$ & + \\
\hline \multirow[t]{2}{*}{ F10 } & $1.42 \mathrm{E}+01$ & $9.97 \mathrm{E}-01$ & 4.18E-01 & $6.90 \mathrm{E}-02$ & 4.72E-02 & $7.55 \mathrm{E}-01$ & \\
\hline & $(1.63 \mathrm{E}+01)$ & (6.49E-01) & (3.89E-01) & (3.57E-02) & $(2.96 \mathrm{E}-02)$ & $(9.51 \mathrm{E}$ & - \\
\hline \multirow[t]{2}{*}{ F11 } & $1.29 \mathrm{E}+03$ & $1.92 \mathrm{E}+03$ & $1.72 \mathrm{E}+03$ & $1.84 \mathrm{E}+03$ & $1.70 \mathrm{E}+03$ & $1.56 \mathrm{E}+03$ & \\
\hline & $(2.68 \mathrm{E}+02)$ & $(2.00 \mathrm{E}+02)$ & $+(2.48 \mathrm{E}+02)$ & $+(2.58 \mathrm{E}+02)$ & $+(2.37 \mathrm{E}+02)$ & $+(2.55 \mathrm{E}+02)$ & + \\
\hline \multirow[t]{2}{*}{ F12 } & $3.45 \mathrm{E}-01$ & $1.63 \mathrm{E}-01$ & $1.88 \mathrm{E}-01$ & 1.12E-01 & $1.76 \mathrm{E}-01$ & $1.40 \mathrm{E}-01$ & \\
\hline & $(7.05 \mathrm{~F}$ & $(2.15 \mathrm{E}-02)$ & $(3.60 \mathrm{E}-02)$ & $(2.46 \mathrm{E}-02)$ & (3.23E-02) & $(2.57 \mathrm{H}$ & - \\
\hline F13 & 8.5 & $2.26 \mathrm{E}-01$ & $2.36 \mathrm{E}-01$ & $2.34 \mathrm{E}-01$ & $2.25 \mathrm{E}-01$ & 1.90 & \\
\hline & $(1.41 \mathrm{E}$ & (3.39E-02) & $(3.141$ & $(2.92 \mathrm{E}-02)$ & (3.66E-02) & $(3.27$ & + \\
\hline F14 & $2.11 \mathrm{E}-01$ & 1.96E-01 & $1.97 \mathrm{E}-01$ & $2.01 \mathrm{E}-01$ & $2.22 \mathrm{E}-01$ & $2.30 \mathrm{E}-01$ & \\
\hline & $(3.96 \mathrm{~F}$ & $(1.54 \mathrm{E}-02)$ & $(2.04 \mathrm{E}-02)$ & (1.50E-02) & (1.96E-02) & $(2.32 \mathrm{E}-02)$ & + \\
\hline F15 & $3.54 \mathrm{E}$ & $8.35 \mathrm{E}+00$ & $6.19 \mathrm{E}+00$ & $6.86 \mathrm{E}+00$ & $6.35 \mathrm{E}+00$ & $4.14 \mathrm{E}+00$ & \\
\hline & $(4.37$ & $(1.38 \mathrm{E}+00)$ & $+(1.11 \mathrm{E}+00)$ & $+(1.24 \mathrm{E}+00)$ & $+(1.03 \mathrm{E}+00)$ & (7.30E-01) & + \\
\hline F16 & $7.34 \mathrm{E}$ & $9.77 \mathrm{E}+00$ & $9.34 \mathrm{E}+00$ & $9.26 \mathrm{E}+00$ & $9.45 \mathrm{E}+00$ & $8.63 \mathrm{E}+00$ & \\
\hline & $(7.15 \mathrm{E}$ & (4.02E-01) & $(3.96 \mathrm{E}-01)$ & $(5.16 \mathrm{E}-01)$ & $(3.50 \mathrm{E}-01)$ & $(5.28 \mathrm{E}-01)$ & + \\
\hline F17 & $3.59 \mathrm{E}$ & $1.87 \mathrm{E}+06$ & $1.90 \mathrm{E}+06$ & $9.95 \mathrm{E}+05$ & $1.71 \mathrm{E}+06$ & $1.58 \mathrm{E}+06$ & \\
\hline & $(2.31 \mathrm{E}+05)$ & $(8.60 \mathrm{E}+05)$ & $+(9.35 \mathrm{E}+05)$ & $+(5.58 \mathrm{E}+05)$ & $+(1.04 \mathrm{E}+06)$ & $+(8.57 \mathrm{E}+05)$ & + \\
\hline F18 & $1.04 \mathrm{E}+03$ & $6.93 \mathrm{E}+02$ & $3.23 \mathrm{E}+03$ & $3.27 \mathrm{E}+02$ & $2.83 \mathrm{E}+02$ & $1.58 \mathrm{E}+03$ & \\
\hline & $(1.541$ & $(5.92 \mathrm{E}+02)$ & $=(2.85 \mathrm{E}+03)$ & $+(1.88 \mathrm{E}+02)$ & $(3.89 \mathrm{E}+02)$ & $+(2.14 \mathrm{E}+03)$ & - \\
\hline F19 & +00 & $7.23 \mathrm{E}+00$ & $6.77 \mathrm{E}+00$ & $6.99 \mathrm{E}+00$ & $6.90 \mathrm{E}+00$ & $6.31 \mathrm{E}+00$ & \\
\hline & $(9.88 \mathrm{H}$ & (6.99E-01) & $(6.7 \mathrm{~s}$ & E-01) & $(7.331$ & $-01)$ & + \\
\hline F20 & 03 & $8.37 \mathrm{E}+03$ & +03 & +03 & $7.90 \mathrm{E}+03$ & +03 & \\
\hline & 03) & $(4.33 \mathrm{E}+03)$ & $(4.15 \mathrm{E}$ & $\mathrm{E}+03)$ & $+03)$ & $+03)$ & + \\
\hline F21 & $6.21 \mathrm{E}+04$ & $1.70 \mathrm{E}+05$ & $2.24 \mathrm{E}+05$ & $1.54 \mathrm{E}+05$ & $1.35 \mathrm{E}+05$ & $2.09 \mathrm{E}+05$ & \\
\hline & & $(9.99 \mathrm{E}+04)$ & $E+05)$ & $\mathrm{E}+05)$ & $(1.01 \mathrm{E}+05)$ & $+05)$ & + \\
\hline F 22 & $9.56 \mathrm{E}+01$ & $3.00 \mathrm{E}+02$ & $2.58 \mathrm{E}+02$ & $3.03 \mathrm{E}+02$ & $2.54 \mathrm{E}+02$ & $2.16 \mathrm{E}+02$ & \\
\hline & $(6.23 \mathrm{E}+01)$ & $(9.85 \mathrm{E}+01)$ & $+(9.56 \mathrm{E}+01)$ & $+(1.04 \mathrm{E}+02)$ & $+(9.75 \mathrm{E}+01)$ & $+(1.04 \mathrm{E}+02)$ & + \\
\hline F23 & $3.15 \mathrm{E}+02$ & $3.15 \mathrm{E}+02$ & $3.15 \mathrm{E}+02$ & $3.15 \mathrm{E}+02$ & $3.15 \mathrm{E}+02$ & $3.15 \mathrm{E}+02$ & \\
\hline & (9.53E-10) & (5.97E-02) & $(1.06 \mathrm{E}-01)$ & (4.47E-02) & (1.09E-01) & $(1.02 \mathrm{E}-01)$ & + \\
\hline F24 & $2.24 \mathrm{E}+02$ & $2.26 \mathrm{E}+02$ & $2.24 \mathrm{E}+02$ & $2.26 \mathrm{E}+02$ & $2.23 E+02$ & $2.26 \mathrm{E}+02$ & \\
\hline & $(6.82)$ & $(5.03 \mathrm{E}+00)$ & $+(1.03 \mathrm{E}+01)$ & $(6.80 \mathrm{E}+00)$ & $+(1.14 \mathrm{E}+01)$ & 1E-01) & - \\
\hline F25 & -02 & $2.09 \mathrm{E}+02$ & $2.08 \mathrm{E}+02$ & $2.06 \mathrm{E}+02$ & $2.08 \mathrm{E}+02$ & $2.07 \mathrm{E}+02$ & \\
\hline & & $(1.18$ & $+(1.16$ & $+(1.2$ & $(8.93 \mathrm{H}$ & $+(1.0$ & + \\
\hline F26 & +02 & $1.00 \mathrm{E}+02$ & $1.00 \mathrm{E}+02$ & $1.00 \mathrm{E}+02$ & $1.00 \mathrm{E}+02$ & $1.00 \mathrm{E}+02$ & \\
\hline & & & $(4.65 \mathrm{E}-02)$ & (7.10E-02) & $(5.62 \mathrm{E}-02)$ & $(4.25 \mathrm{E}-02)$ & + \\
\hline F27 & $3.52 \mathrm{E}+02$ & $4.02 \mathrm{E}+02$ & $4.02 \mathrm{E}+02$ & $4.07 \mathrm{E}+02$ & $4.11 \mathrm{E}+02$ & $4.08 \mathrm{E}+02$ & \\
\hline & $(4.46 \mathrm{E}+01)$ & $(5.62 \mathrm{E}+01)$ & $(5.62 \mathrm{E}+01)$ & $(2.90 \mathrm{E}+00)$ & $(3.74 \mathrm{E}+00)$ & $(4.07 \mathrm{E}+00)$ & + \\
\hline F28 & $8.07 \mathrm{E}+02$ & $1.22 \mathrm{E}+03$ & $9.35 \mathrm{E}+02$ & $1.19 \mathrm{E}+03$ & $9.43 \mathrm{E}+02$ & $8.79 \mathrm{E}+02$ & \\
\hline & $(3.58 \mathrm{E}+01)$ & $(1.60 \mathrm{E}+02)$ & $+(5.86 \mathrm{E}+01)$ & $+(1.72 \mathrm{E}+02)$ & $+(5.07 \mathrm{E}+01)$ & $(4.80 \mathrm{E}+01)$ & + \\
\hline F29 & $1.29 \mathrm{E}+03$ & $1.01 \mathrm{E}+03$ & $1.12 \mathrm{E}+03$ & $9.64 \mathrm{E}+02$ & $1.14 \mathrm{E}+03$ & $1.25 \mathrm{E}+03$ & \\
\hline & $(2.78 \mathrm{E}+02)$ & $(7.28 \mathrm{E}+01)$ & $(1.57 \mathrm{E}+02)$ & $(6.98 \mathrm{E}+01)$ & $(1.06 \mathrm{E}+02)$ & $(3.19 \mathrm{E}+02)$ & - \\
\hline F30 & $2.19 \mathrm{E}+03$ & $2.69 \mathrm{E}+03$ & $2.77 \mathrm{E}+03$ & $2.26 \mathrm{E}+03$ & $3.20 \mathrm{E}+03$ & $2.94 \mathrm{E}+03$ & \\
\hline & $(6.20 \mathrm{E}+02)$ & $(6.43 \mathrm{E}+02)$ & $(7.67 \mathrm{E}+02)$ & $(5.97 \mathrm{E}+02)$ & $(8.76 \mathrm{E}+02)$ & $(7.87 \mathrm{E}+02)$ & + \\
\hline F01 F03 & $+/=/-$ & $2-0-1$ & $2-0-1$ & $1-1-1$ & $2-0-1$ & $2-0-1$ & \\
\hline H $\sim \mathrm{F} 16$ & $+/=/-$ & $7-0-6$ & $7-0-6$ & $7-1-5$ & $8-0-5$ & $8-0-5$ & \\
\hline $17 \sim \mathrm{F} 22$ & $+/=/-$ & $5-1-0$ & $6-0-0$ & $5-1-0$ & $6-0-0$ & $5-0-1$ & \\
\hline F23 F F30 & $+1=1-$ & $7-0-1$ & $7-0-1$ & $6-1-1$ & $7-1-0$ & $6-0-2$ & \\
\hline Total & & $21-1-8$ & $22-0-8$ & $19-4-7$ & $23-1-6$ & $21-0-9$ & \\
\hline
\end{tabular}

The symbols,$+=$ and - mean that BFL-PSO is significantly superior, similar or inferior to its competitor, respectively, according to the Wilcoxon rank sum test at $\alpha=0.05$ significance level.

The best results in terms of mean function error are highlighted in bold. 


\subsection{BFL-PSO vs. two hybrid PSO-ABC algorithms}

The BFL-PSO is further compared with two recently-developed hybrid PSO-ABC algorithms, i.e., PS-MEABC [43] and PS-ABC [39]. PS-MEABC employs the global best solution and an elitist archive strategy to modify the solutions in ABC [43]. PS-ABC combines one local search phase from PSO and two search phases from ABC to form a hybrid algorithm [39].

Table 7 presents the comparison results of BFL-PSO and the hybrid PSO-ABC algorithms.

First, BFL-PSO is compared with PS-MEABC. For the unimodal functions, BFL-PSO performs better than PS-MEABC on none function, but worse on 2 functions. For the simple multimodal, BFL-PSO performs better than PS-MEABC on 7 functions, but worse on 6 functions. For the hybrid functions BFL-PSO performs better than PS-MEABC on 2 functions, but worse on 2 functions. For the composite functions, BFL-PSO performs better than PS-MEABC on 6 functions, but worse on 1 function.

Then, BFL-PSO is compared with PS-ABC. For the unimodal functions, BFL-PSO performs better than PS-ABC on 1 function, but worse on 1 function. For the simple multimodal, BFLPSO performs better than PS-ABC on 13 functions, but worse on none function. For the hybrid functions BFL-PSO performs better than PS-ABC on 5 functions, but worse on none function. For the composite functions, BFL-PSO performs better than PS-ABC on 8 functions, but worse on none function.

In summary, the above comparisons show that BFL-PSO exhibits competitive performance compared with two recently hybrid PSO-ABC algorithms. In particular, BFL-PSO achieves much better results on the complex composite functions. 
Table 7: Comparison results of BFL-PSO with two hybrid PSO-ABC algorithms on CEC 2014 benchmark functions

\begin{tabular}{|c|c|c|c|c|c|c|c|c|}
\hline \multicolumn{3}{|c|}{ BFL-PSO } & \multicolumn{2}{|l|}{ PS-MEABC } & \multicolumn{3}{|c|}{ PS-ABC } & \\
\hline & Mean & SD & Mean & $\mathrm{SD}$ & & Mean & $\mathrm{SD}$ & \\
\hline F01 & $3.26 \mathrm{E}+06$ & $(1.48 \mathrm{E}+06)$ & $3.21 \mathrm{E}+06$ & $(1.43 \mathrm{E}+06)$ & $=$ & $5.62 \mathrm{E}+06$ & $(6.75 \mathrm{E}+06)$ & $=$ \\
\hline F02 & $9.09 \mathrm{E}+03$ & $(6.24 \mathrm{E}+03)$ & $0.00 \mathrm{E}+00$ & $(0.00 \mathrm{E}+00)$ & - & $3.30 \mathrm{E}+02$ & $(3.95 \mathrm{E}+02)$ & - \\
\hline F03 & $1.50 \mathrm{E}+01$ & $(3.67 \mathrm{E}+01)$ & $0.00 E+00$ & $(0.00 \mathrm{E}+00)$ & - & $5.52 \mathrm{E}+02$ & $(1.02 \mathrm{E}+03)$ & + \\
\hline F04 & $8.79 \mathrm{E}+01$ & $(2.48 \mathrm{E}+01)$ & $6.84 \mathrm{E}+01$ & $(3.34 \mathrm{E}+01)$ & - & $1.41 \mathrm{E}+02$ & $(7.46 \mathrm{E}+01)$ & + \\
\hline F05 & $2.03 \mathrm{E}+01$ & $(5.25 \mathrm{E}-02)$ & $2.02 \mathrm{E}+01$ & $(3.78 \mathrm{E}-02)$ & - & $2.09 \mathrm{E}+01$ & $(4.48 \mathrm{E}-02)$ & + \\
\hline F06 & $1.38 \mathrm{E}+00$ & (8.75E-01) & $1.31 \mathrm{E}+01$ & $(1.52 \mathrm{E}+00)$ & + & $1.81 \mathrm{E}+01$ & $(3.30 \mathrm{E}+00)$ & + \\
\hline F07 & $0.00 \mathrm{E}+00$ & $(0.00 \mathrm{E}+00)$ & $1.16 \mathrm{E}-05$ & $(2.46 \mathrm{E}-05)$ & + & $9.21 \mathrm{E}-03$ & $(1.18 \mathrm{E}-02)$ & + \\
\hline F08 & 3.91E-01 & $(5.29 \mathrm{E}-01)$ & $0.00 \mathrm{E}+00$ & $(0.00 \mathrm{E}+00)$ & - & $5.75 \mathrm{E}+01$ & $(1.56 \mathrm{E}+01)$ & + \\
\hline F09 & $1.69 \mathrm{E}+01$ & $(3.12 \mathrm{E}+00)$ & $5.87 \mathrm{E}+01$ & $(9.54 \mathrm{E}+00)$ & + & $8.45 \mathrm{E}+01$ & $(2.32 \mathrm{E}+01)$ & + \\
\hline F10 & $1.42 \mathrm{E}+01$ & $(1.63 \mathrm{E}+01)$ & $2.71 \mathrm{E}+00$ & $(1.15 \mathrm{E}+00)$ & - & $1.85 \mathrm{E}+03$ & $(6.15 \mathrm{E}+02)$ & + \\
\hline F11 & $1.29 \mathrm{E}+03$ & $(2.68 \mathrm{E}+02)$ & $1.82 \mathrm{E}+03$ & $(2.31 \mathrm{E}+02)$ & + & $3.38 \mathrm{E}+03$ & $(5.76 \mathrm{E}+02)$ & + \\
\hline F12 & 3.45E-01 & $(7.05 \mathrm{E}-02)$ & $2.65 \mathrm{E}-01$ & $(5.24 \mathrm{E}-02)$ & - & $1.45 \mathrm{E}+00$ & (6.45E-01) & + \\
\hline F13 & $8.57 \mathrm{E}-02$ & $(1.41 \mathrm{E}-02)$ & $2.78 \mathrm{E}-01$ & $(4.22 \mathrm{E}-02)$ & + & $3.16 \mathrm{E}-01$ & $(6.44 \mathrm{E}-02)$ & + \\
\hline F14 & $2.11 \mathrm{E}-01$ & $(3.96 \mathrm{E}-02)$ & 1.93E-01 & $(2.41 \mathrm{E}-02)$ & - & $3.98 \mathrm{E}-01$ & $(1.54 \mathrm{E}-01)$ & + \\
\hline F15 & $3.54 \mathrm{E}+00$ & (4.37E-01) & $6.87 \mathrm{E}+00$ & $(1.85 \mathrm{E}+00)$ & + & $1.32 \mathrm{E}+01$ & $(4.67 \mathrm{E}+00)$ & + \\
\hline F16 & $7.34 \mathrm{E}+00$ & $(7.15 \mathrm{E}-01)$ & $9.83 \mathrm{E}+00$ & $(3.08 \mathrm{E}-01)$ & + & $1.13 \mathrm{E}+01$ & $(6.58 \mathrm{E}-01)$ & + \\
\hline F17 & $3.59 \mathrm{E}+05$ & $(2.31 \mathrm{E}+05)$ & $3.24 \mathrm{E}+05$ & $(1.97 \mathrm{E}+05)$ & $=$ & $4.83 \mathrm{E}+05$ & $(7.74 \mathrm{E}+05)$ & + \\
\hline F18 & $1.04 \mathrm{E}+03$ & $(1.54 \mathrm{E}+03)$ & $1.39 \mathrm{E}+03$ & $(1.73 \mathrm{E}+03)$ & $=$ & $4.29 \mathrm{E}+03$ & $(3.78 \mathrm{E}+03)$ & + \\
\hline F19 & $4.56 \mathrm{E}+00$ & $(9.88 \mathrm{E}-01)$ & $6.53 \mathrm{E}+00$ & $(6.60 \mathrm{E}-01)$ & + & $1.33 \mathrm{E}+01$ & $(9.24 \mathrm{E}+00)$ & + \\
\hline F20 & $1.06 \mathrm{E}+03$ & $(1.08 \mathrm{E}+03)$ & $7.82 \mathrm{E}+01$ & $(4.82 \mathrm{E}+01)$ & - & $4.08 \mathrm{E}+03$ & $(3.34 \mathrm{E}+03)$ & + \\
\hline F21 & $6.21 \mathrm{E}+04$ & $(5.14 \mathrm{E}+04)$ & $3.35 \mathrm{E}+04$ & $(3.19 \mathrm{E}+04)$ & - & $1.26 \mathrm{E}+05$ & $(3.61 \mathrm{E}+05)$ & $=$ \\
\hline F22 & $9.56 \mathrm{E}+01$ & $(6.23 \mathrm{E}+01)$ & $1.79 \mathrm{E}+02$ & $(8.92 \mathrm{E}+01)$ & + & $3.80 \mathrm{E}+02$ & $(2.06 \mathrm{E}+02)$ & + \\
\hline F23 & $3.15 \mathrm{E}+02$ & $(9.53 \mathrm{E}-10)$ & $3.15 \mathrm{E}+02$ & $(4.53 \mathrm{E}-06)$ & + & $3.16 \mathrm{E}+02$ & $(4.59 \mathrm{E}-01)$ & + \\
\hline F24 & $2.24 \mathrm{E}+02$ & (6.82E-01) & $2.27 \mathrm{E}+02$ & $(9.00 \mathrm{E}-01)$ & + & $2.38 \mathrm{E}+02$ & $(6.79 \mathrm{E}+00)$ & + \\
\hline F 25 & $2.05 \mathrm{E}+02$ & (4.75E-01) & $2.09 \mathrm{E}+02$ & $(1.37 \mathrm{E}+00)$ & + & $2.16 \mathrm{E}+02$ & $(5.45 \mathrm{E}+00)$ & + \\
\hline F26 & $1.00 \mathrm{E}+02$ & (1.99E-02) & $1.00 \mathrm{E}+02$ & $(4.33 \mathrm{E}-02)$ & + & $1.31 \mathrm{E}+02$ & $(4.56 \mathrm{E}+01)$ & + \\
\hline $\mathrm{F} 27$ & $3.52 \mathrm{E}+02$ & $(4.46 \mathrm{E}+01)$ & $4.12 \mathrm{E}+02$ & $(4.90 \mathrm{E}+00)$ & + & $7.40 \mathrm{E}+02$ & $(2.32 \mathrm{E}+02)$ & + \\
\hline F28 & $8.07 \mathrm{E}+02$ & $(3.58 \mathrm{E}+01)$ & $9.33 \mathrm{E}+02$ & $(3.74 \mathrm{E}+01)$ & + & $1.71 \mathrm{E}+03$ & $(5.52 \mathrm{E}+02)$ & + \\
\hline F29 & $1.29 \mathrm{E}+03$ & $(2.78 \mathrm{E}+02)$ & $1.23 \mathrm{E}+03$ & $(2.52 \mathrm{E}+02)$ & $=$ & $3.29 \mathrm{E}+06$ & $(7.79 \mathrm{E}+06)$ & + \\
\hline F30 & $2.19 \mathrm{E}+03$ & $(6.20 \mathrm{E}+02)$ & $1.90 E+03$ & $(5.48 \mathrm{E}+02)$ & - & $7.88 \mathrm{E}+03$ & $(6.67 \mathrm{E}+03)$ & + \\
\hline F01 F03 & $+/=/-$ & & $0-1-2$ & & & $1-1-1$ & & \\
\hline $\mathrm{F} 04 \sim \mathrm{F} 16$ & $+/=/-$ & & $7-0-6$ & & & $13-0-0$ & & \\
\hline $\mathrm{F} 17 \sim \mathrm{F} 22$ & $+/=/-$ & & $2-2-2$ & & & $5-1-0$ & & \\
\hline F23 F 30 & $+1=/-$ & & $6-1-1$ & & & $8-0-0$ & & \\
\hline Total & $+/=/-$ & & 15-4-11 & & & $27-2-1$ & & \\
\hline
\end{tabular}

The symbols,$+=$ and - mean that BFL-PSO is significantly superior, similar or inferior to its competitor, respectively, according to the Wilcoxon rank sum test at $\alpha=0.05$ significance level

The best results in terms of mean function error are highlighted in bold.

\subsection{Friedman ranks and runtime analysis}

Table 8 presents the Friedman ranks of all the compared algorithms on four groups of CEC2014 functions. For the unimodal functions, EPSO and PS-MEABC achieve the best rank (2.33), and BLF-PSO achieves the fifth rank (6.67). For the simple multimodal functions, BLFPSO achieves the best rank (4.62). For the hybrid functions, EPSO achieves the best rank (2.67), and BLF-PSO achieves the second best rank (3.67). For the composite functions, BFLPSO achieves the best rank (2.81).

When considering all 30 functions, BFL-PSO achieves the best rank (4.15), BLPSO the second (5.38), EPSO the third (5.45), followed by PS-MEABC and others. In addition, the statistical test is conducted at $\alpha=0.05$ significance level in Table 9. Based on the unadjusted $p$-value given in Table 9, BFL-PSO is significantly superior to most of the compared algorithms excluding BLPSO, EPSO and PS-MEABC. 
Table 10 presents the average runtime of all the algorithms on 30 functions. Fig. 4 plots the bar chart of the average runtime on function F01. BFL-PSO introduces two additional search phases (i.e., onlooker learning and scout learning), which may bring more runtime in BFL-PSO. From Fig.4, the runtime of BFL-PSO is 13.04 seconds, which is larger than SRPSO, SLPSO and DFSABC. However, the runtime of BFL-PSO is less than all the other algorithms including CLPSO, EPSO and BLPSO.

Table 8: Friedman test of mean error values on four groups of functions

\begin{tabular}{|c|c|c|c|c|c|c|c|c|c|c|}
\hline Algorithm & $\begin{array}{l}\text { Unimodal } \\
\text { Rank }\end{array}$ & F01 F03 & $\begin{array}{l}\text { Multimodal } \\
\text { Rank }\end{array}$ & $\mathrm{F} 04 \sim \mathrm{F} 16$ & $\begin{array}{l}\text { Hybrid: } \\
\text { Rank }\end{array}$ & $\mathrm{F} 17 \sim \mathrm{F} 22$ & $\begin{array}{l}\text { Composition: } \\
\text { Rank }\end{array}$ & F23 F30 & $\begin{array}{l}\text { Total: } \\
\text { Rank }\end{array}$ & F01 F30 \\
\hline BFL-PSO & 6.67 & 5 & 4.62 & 1 & 3.67 & 2 & 2.81 & 1 & 4.15 & 1 \\
\hline CLPSO & 7.00 & 6 & 8.31 & 11 & 6.17 & 5 & 6.88 & 5 & 7.37 & 9 \\
\hline SRPSO & 5.67 & 3 & 10.15 & 12 & 6.33 & 6 & 8.50 & 12 & 8.50 & 12 \\
\hline SLPSO & 9.33 & 11 & 7.69 & 9 & 7.83 & 7 & 7.19 & 8 & 7.75 & 10 \\
\hline EPSO & 2.33 & 1 & 8.00 & 10 & 2.67 & 1 & 4.56 & 3 & 5.45 & 3 \\
\hline BLPSO & 8.00 & 8 & 6.08 & 6 & 4.33 & 4 & 4.06 & 2 & 5.38 & 2 \\
\hline $\mathrm{ABC}$ & 9.33 & 12 & 6.38 & 7 & 10.17 & 12 & 7.88 & 10 & 7.83 & 11 \\
\hline GABC & 8.33 & 9 & 5.38 & 5 & 10.67 & 13 & 7.38 & 9 & 7.27 & 8 \\
\hline qABC & 7.00 & 7 & 5.00 & 3 & 8.83 & 10 & 6.75 & 4 & 6.43 & 5 \\
\hline ABCVSS & 9.67 & 13 & 4.69 & 2 & 8.17 & 8 & 7.13 & 6 & 6.53 & 6 \\
\hline DFSABC & 6.33 & 4 & 5.31 & 4 & 8.17 & 9 & 7.88 & 11 & 6.67 & 7 \\
\hline PS-MEABC & 2.33 & 2 & 6.92 & 8 & 4.00 & 3 & 7.13 & 7 & 5.93 & 4 \\
\hline PS-ABC & 9.00 & 10 & 12.46 & 13 & 10.00 & 11 & 12.88 & 13 & 11.73 & 13 \\
\hline
\end{tabular}

Table 9: Adjusted $p$-values obtained by Bonferroni-Dunn and Holm procedures for BFL-PSO and the compared algorithms

\begin{tabular}{llll}
\hline BFL-PSO vs. & unadjusted $p$ & Bonferroni $p$ & Holm $p$ \\
\hline PS-ABC & 0.0000 & 0.0000 & 0.0000 \\
SRPSO & 0.0000 & 0.0002 & 0.0002 \\
ABC & 0.0002 & 0.0030 & 0.0025 \\
SLPSO & 0.0003 & 0.0041 & 0.0031 \\
CLPSO & 0.0014 & 0.0166 & 0.0110 \\
GABC & 0.0019 & 0.0233 & 0.0136 \\
DFSABC & 0.0123 & 0.1479 & 0.0739 \\
ABCVSS & 0.0178 & 0.2133 & 0.0889 \\
qABC & 0.0232 & 0.2779 & 0.0926 \\
PS-MEABC & 0.0761 & 0.9137 & 0.2284 \\
EPSO & 0.1961 & 2.3528 & 0.3921 \\
BLPSO & 0.2200 & 2.6400 & 0.3921 \\
\hline
\end{tabular}


Table 10: The average run time (in seconds) of the compared algorithms on all CEC2014 functions

\begin{tabular}{|c|c|c|c|c|c|c|c|c|c|c|c|c|c|}
\hline & BFL-PSO & CLPSO & SRPSO & SLPSO & EPSO & BLPSO & $\mathrm{ABC}$ & GABC & qABC & ABCVSS & DFSABC & PS-MEABC & PS-ABC \\
\hline F01 & 13.04 & 16.40 & 4.88 & 6.39 & 25.01 & 17.42 & 14.58 & 14.87 & 20.71 & 16.53 & 12.57 & 13.99 & 16.59 \\
\hline F02 & 11.41 & 14.42 & 4.46 & 6.15 & 23.83 & 15.39 & 14.60 & 14.54 & 20.40 & 16.38 & 11.90 & 12.95 & 15.10 \\
\hline F03 & 11.86 & 14.95 & 4.47 & 5.66 & 24.19 & 16.57 & 14.63 & 14.85 & 19.76 & 16.37 & 11.98 & 12.77 & 15.21 \\
\hline F04 & 11.67 & 15.42 & 4.44 & 5.83 & 25.31 & 15.78 & 13.75 & 13.68 & 18.57 & 16.04 & 11.91 & 12.89 & 15.57 \\
\hline F05 & 13.27 & 16.49 & 4.65 & 5.95 & 29.02 & 19.73 & 13.73 & 13.82 & 18.47 & 16.56 & 12.23 & 12.99 & 13.73 \\
\hline F06 & 29.72 & 35.27 & 22.06 & 25.29 & 43.90 & 35.30 & 32.56 & 32.69 & 37.95 & 35.82 & 30.70 & 32.04 & 32.37 \\
\hline F07 & 11.32 & 14.67 & 4.71 & 5.86 & 24.86 & 16.22 & 13.54 & 13.63 & 18.56 & 16.51 & 11.95 & 12.96 & 13.72 \\
\hline F08 & 11.55 & 14.67 & 4.43 & 5.62 & 24.06 & 16.86 & 13.17 & 13.22 & 18.14 & 16.20 & 11.55 & 12.65 & 13.47 \\
\hline F09 & 12.39 & 15.85 & 4.65 & 5.76 & 25.53 & 17.67 & 13.51 & 13.63 & 18.50 & 16.28 & 12.00 & 12.93 & 13.83 \\
\hline F10 & 13.18 & 16.37 & 5.10 & 6.86 & 28.08 & 18.30 & 14.02 & 13.97 & 19.11 & 16.99 & 12.38 & 13.64 & 14.78 \\
\hline F11 & 13.63 & 17.38 & 5.33 & 6.63 & 28.83 & 20.65 & 14.46 & 14.51 & 19.57 & 17.15 & 12.98 & 14.06 & 15.26 \\
\hline F12 & 16.38 & 20.27 & 7.85 & 9.98 & 33.38 & 23.43 & 16.87 & 16.89 & 22.01 & 19.87 & 15.44 & 16.47 & 17.32 \\
\hline F13 & 11.69 & 15.45 & 4.44 & 5.49 & 27.58 & 17.20 & 13.22 & 13.29 & 18.28 & 16.28 & 11.83 & 12.68 & 13.20 \\
\hline F14 & 11.66 & 15.26 & 4.47 & 5.77 & 27.07 & 16.95 & 13.35 & 13.28 & 18.26 & 16.36 & 11.82 & 12.76 & 13.29 \\
\hline F15 & 11.65 & 15.25 & 4.63 & 5.66 & 24.73 & 16.79 & 13.56 & 13.66 & 18.85 & 16.43 & 12.04 & 12.95 & 14.81 \\
\hline F16 & 12.52 & 16.63 & 4.70 & 5.76 & 28.18 & 18.96 & 13.55 & 13.57 & 18.66 & 16.40 & 12.41 & 13.18 & 14.03 \\
\hline F17 & 12.86 & 16.62 & 4.94 & 6.07 & 26.74 & 19.02 & 14.80 & 15.03 & 20.70 & 16.91 & 12.84 & 14.17 & 15.98 \\
\hline F18 & 11.98 & 15.77 & 4.60 & 5.87 & 89.56 & 17.38 & 14.49 & 14.57 & 20.62 & 16.48 & 12.45 & 13.07 & 15.59 \\
\hline F19 & 15.99 & 20.52 & 8.38 & 10.39 & 118.00 & 21.39 & 17.67 & 17.83 & 22.85 & 20.92 & 16.39 & 17.24 & 18.34 \\
\hline F20 & 12.20 & 16.38 & 4.66 & 5.97 & 101.21 & 17.95 & 14.08 & 14.20 & 19.31 & 16.51 & 12.49 & 13.26 & 15.84 \\
\hline $\mathrm{F} 21$ & 12.80 & 16.48 & 4.91 & 6.29 & 104.67 & 18.89 & 14.87 & 14.91 & 20.69 & 16.77 & 12.77 & 14.01 & 15.47 \\
\hline F22 & 13.37 & 17.29 & 5.20 & 6.50 & 110.45 & 19.37 & 14.38 & 14.52 & 19.65 & 17.36 & 13.24 & 13.95 & 15.31 \\
\hline F23 & 16.41 & 19.46 & 8.43 & 10.26 & 129.88 & 20.60 & 17.61 & 17.86 & 22.65 & 20.64 & 16.24 & 17.29 & 20.51 \\
\hline F24 & 14.37 & 18.12 & 7.24 & 8.73 & 107.19 & 19.47 & 16.36 & 16.48 & 21.43 & 19.61 & 15.20 & 16.00 & 17.14 \\
\hline F25 & 16.12 & 20.60 & 7.86 & 9.48 & 138.22 & 22.32 & 17.15 & 17.38 & 22.22 & 20.17 & 15.97 & 16.72 & 18.55 \\
\hline F26 & 36.19 & 40.11 & 27.85 & 32.83 & 201.52 & 42.61 & 37.92 & 38.15 & 43.64 & 41.76 & 36.66 & 38.45 & 38.55 \\
\hline $\mathrm{F} 27$ & 34.93 & 40.55 & 27.40 & 29.41 & 193.51 & 41.36 & 37.84 & 38.29 & 43.71 & 41.50 & 36.63 & 37.96 & 38.51 \\
\hline F28 & 18.06 & 23.00 & 9.65 & 11.67 & 169.50 & 24.07 & 19.20 & 19.37 & 24.70 & 22.17 & 18.11 & 18.79 & 21.17 \\
\hline F29 & 20.67 & 25.03 & 11.10 & 13.02 & 190.03 & 27.31 & 21.53 & 21.66 & 27.40 & 24.52 & 19.77 & 20.68 & 22.87 \\
\hline F30 & 16.72 & 22.01 & 7.75 & 9.42 & 48.39 & 21.64 & 17.90 & 17.95 & 23.83 & 20.66 & 16.23 & 16.99 & 20.62 \\
\hline
\end{tabular}

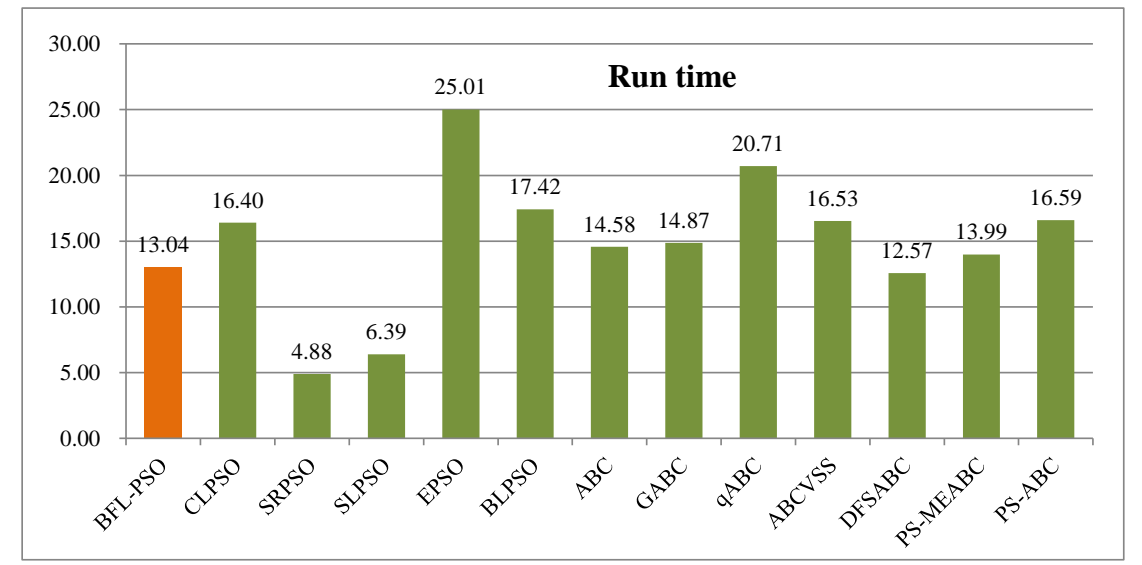

Figure 4: The average runtime (in seconds) of all the algorithms on function F01

\subsection{Convergence analysis}

Fig.5 plots the convergence graphs of BFL-PSO and five PSO algorithms on 12 representative functions. It can be observed that BFL-PSO has the second fastest convergence speed (only after SLPSO), but it can achieve the best solution accuracy on most functions including F07, F09, F13, F16, F22, F25, F27 and F28. SLPSO has the fastest convergence speed on most functions, 
but its solution accuracy is worse than BFL-PSO. EPSO has moderate convergence speed, and achieves the most accurate solutions on F01, F03 and F17. CLPSO and SRPSO have the slowest convergence speed, and their solution accuracy is also not efficient on most functions.

Fig. 6 plots the convergence graphs of BFL-PSO and five ABC algorithms on 12 representative functions. It can be observed that BFL-PSO can convergence to the best solution accuracy compared with the five ABC algorithms on most functions including F01, F03, F06, F07, F09, F13, F17, F19, F21, F27 and F28.

Fig.7 plots the convergence graphs of BFL-PSO and two hybrid PSO-ABC algorithms on 12 representative functions. It can be observed that BFL-PSO has advantages on functions including F06, F07, F09, F11, F13, F15, F18, F19, F22 and F27. PS-MEABC has advantages on two unimodal functions F02 and F03.

Based on the above comparisons, it can be concluded that BFL-PSO also has competitive performance in terms of convergence, and it can converge to the most accurate solutions on the selected representative functions. 

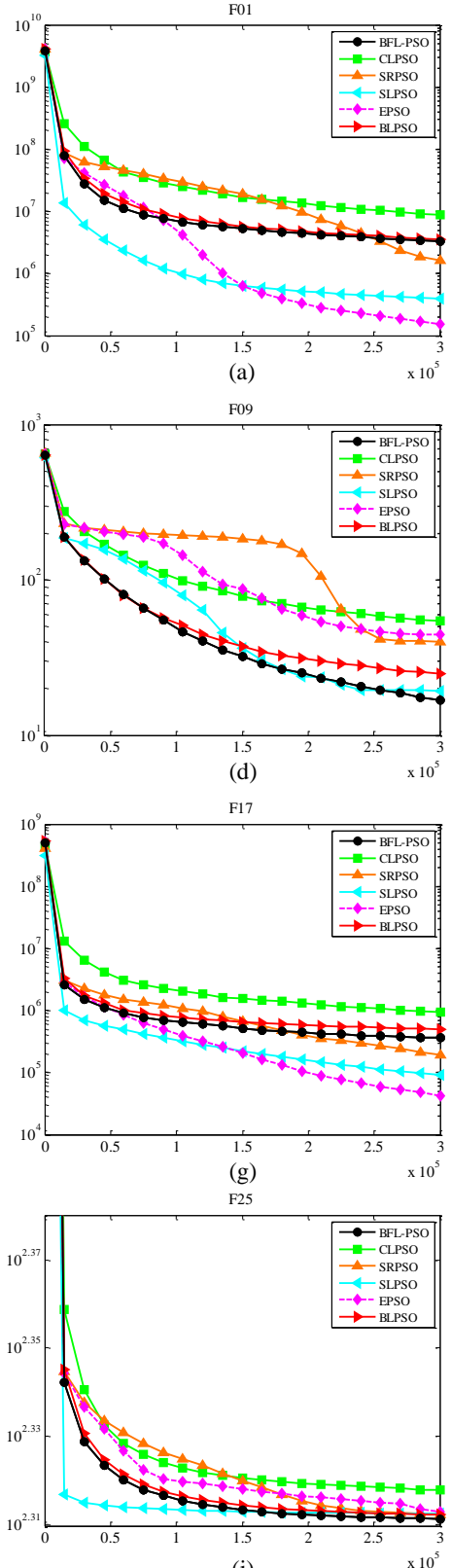

(j)
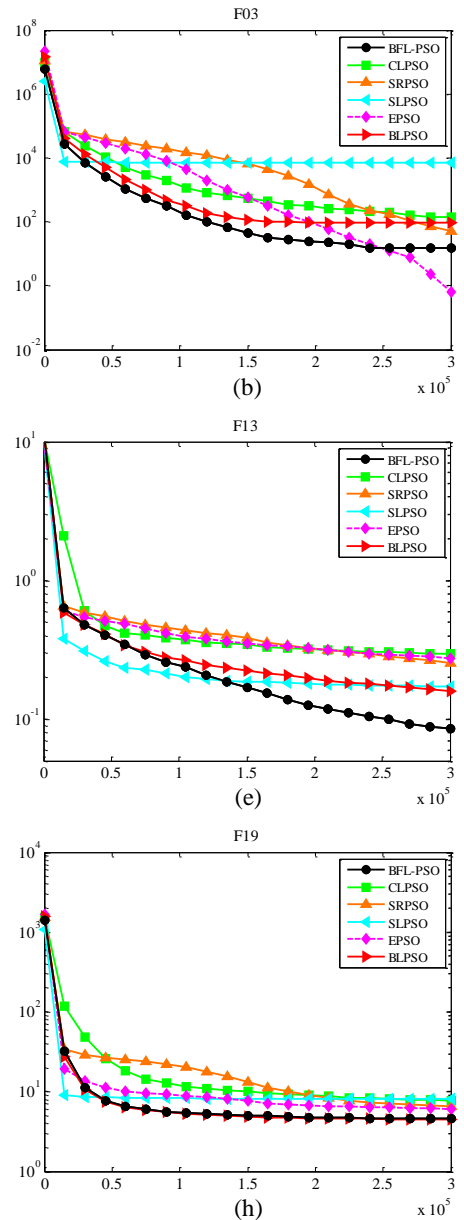

(h)

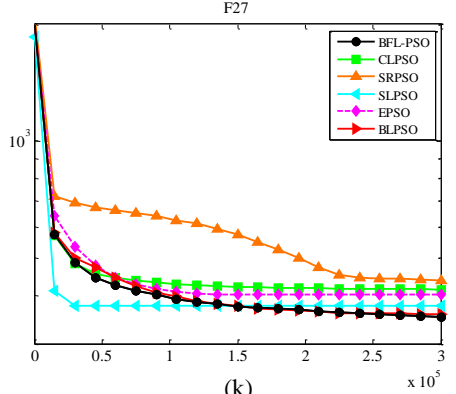

(k)

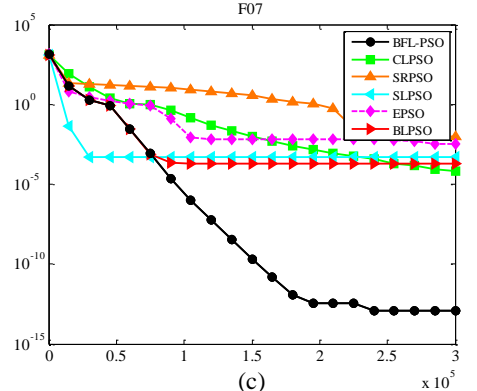

(c)

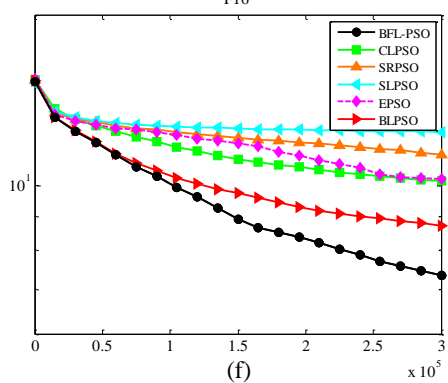

F22

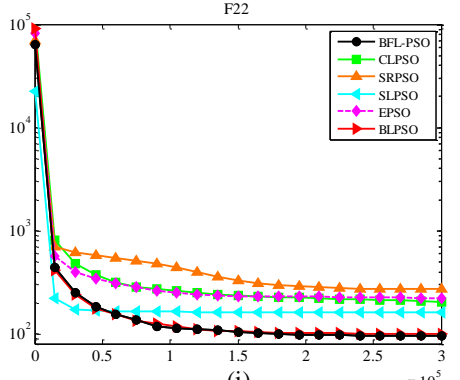

(i)

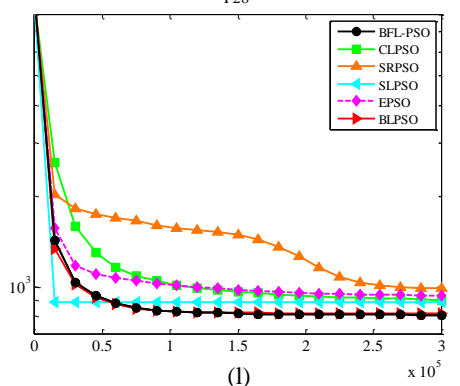

Figure 5: Convergence graphs of BLF-PSO and the compared PSO algorithms 

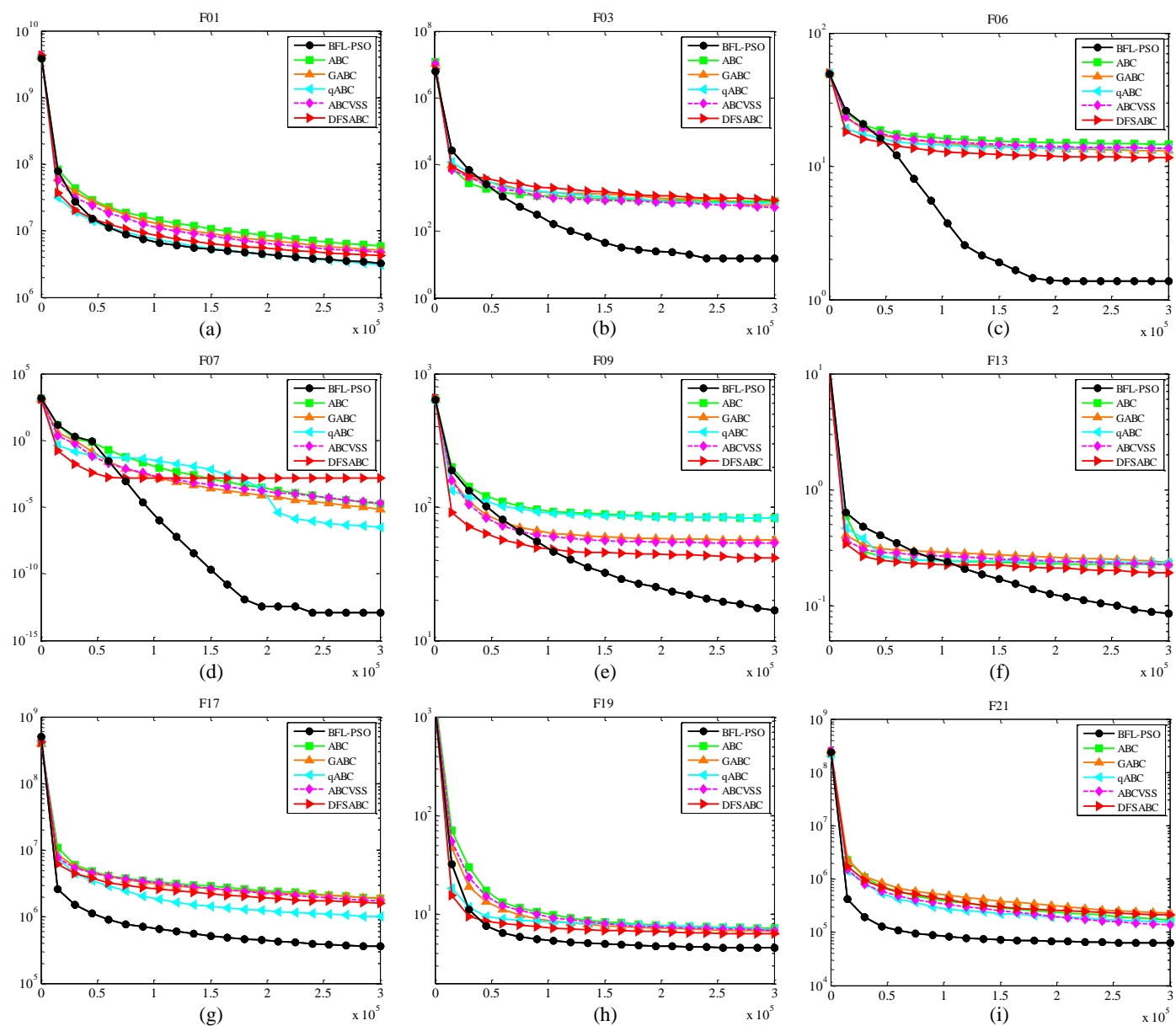

F24
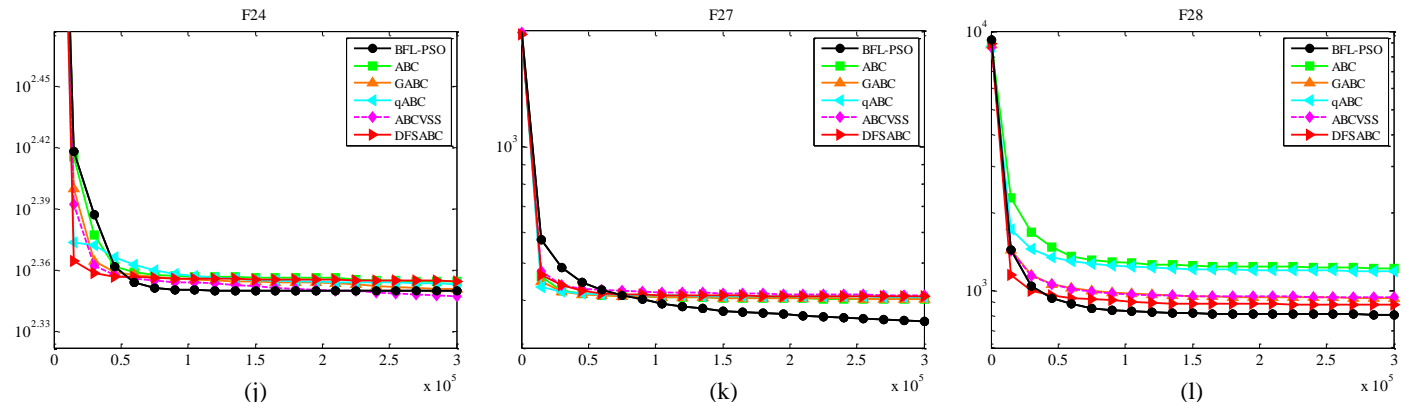

Figure 6: Convergence graphs of BLF-PSO and the compared ABC algorithms 

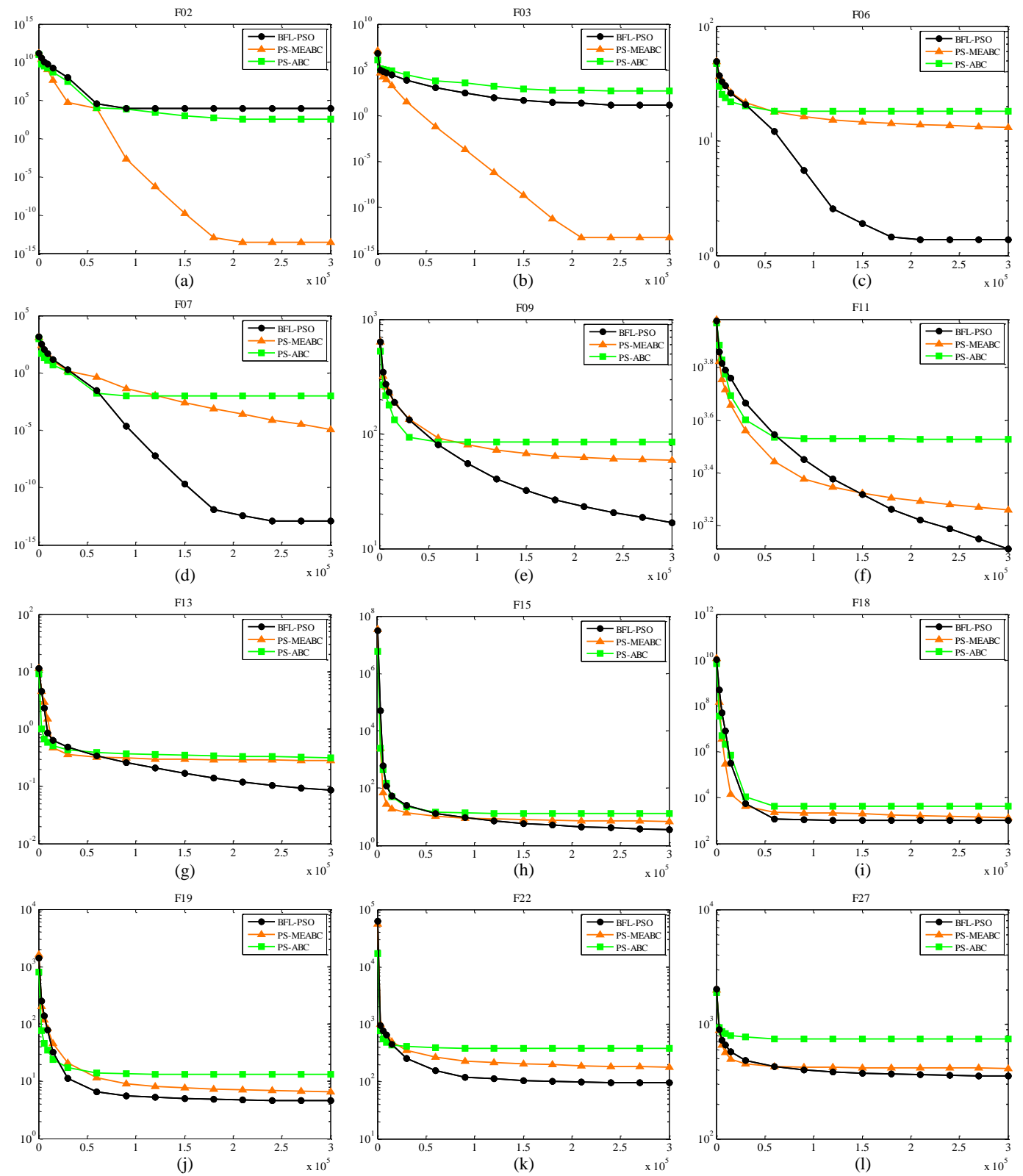

Figure 7: Convergence graphs of BLF-PSO and the hybrid PSO-ABC algorithms

\section{Application to power economic dispatch problems}

To verify the performance of BFL-PSO in solving real-world problem, BFL-PSO is applied to solve power economic dispatch (PED) problems. 


\subsection{Formulation of PED problem}

The PED problem aims to minimize the fuel costs by allocating optimal power output among different generators. At the same time, various generator constraints need to be satisfied [5]].

The objective function of the PED problem is formulated as:

$$
\begin{aligned}
& \operatorname{minimize} F=\sum_{i=1}^{N T} F_{i}\left(P_{i}\right) \\
& F_{i}\left(P_{i}\right)=a_{i}+b_{i} P_{i}+c_{i} P_{i}^{2}+\left|e_{i} \sin \left(f_{i}\left(P_{i}^{\text {min }}-P_{i}\right)\right)\right|
\end{aligned}
$$

where $F$ is the total fuel cost, $F_{i}$ is the fuel cost of the $i$-th generator, $P_{i}$ is the power output of the $i$-th generator, and $a_{i}, b_{i}, c_{i}, e_{i}$ and $f_{i}$ are the fuel cost efficient of the $i$-th generator.

Power balance constraint: the total real power output of all generators should be equal to the total system demand $\left(P_{D}\right)$ plus the total transmission network loss $\left(P_{L}\right)$, i.e.,

$$
\sum_{i=1}^{N T} P_{i}=P_{D}+P_{L}
$$

Generator capacity constraint: the real power output of each generator should be within its minimum boundary $\left(P_{i}^{\min }\right)$ and maximum boundary $\left(P_{i}^{\max }\right)$, i.e.,

$$
P_{i}^{\min } \leq P_{i} \leq P_{i}^{\max }
$$

Ramp-rate constraints: the operating range of each generator is restricted by its ramp-rate limit. The increase and decrease in generation are limited by:

$$
P_{i}-P_{i}^{0} \leq U R_{i}
$$

$$
P_{i}^{0}-P_{i} \leq D R_{i}
$$

where $P_{i}^{0}$ is the previous power output, $U R_{i}$ and $D R_{i}$ are the up-ramp and down-ramp limits, respectively.

Prohibited operating zones (POZs): The feasible operating zones of the $i$-th generator are described as follows:

$$
P_{i} \in\left\{\begin{array}{l}
P_{i}^{\min } \leq P_{i} \leq P_{i, 1}^{l} \\
P_{i, k-1}^{u} \leq P_{i} \leq P_{i, k}^{l} \quad, k=2,3, \cdots, n_{i}, i=1,2, \cdots, N T \\
P_{i, n_{i}}^{u} \leq P_{i} \leq P_{i}^{\max }
\end{array}\right.
$$


where $n_{i}$ is the number of POZs of $i$-th generator. $P_{i, k}^{l}$ and $P_{i, k}^{u}$ are the lower and upper power output of the $k$-th POZ of the $i$-th generator, respectively.

\subsection{Simulation results}

Two PED problems are solved by the BFL-PSO algorithm. They are:

- Case 1: 6 unit system [52, 5:3]

- Case 2: 20 unit system [11, 54]

Table 11 presents the statistical results of BFL-PSO for the 6 unit PED problem. The results of BLPSO [5.2], ST-IRDPSO (improved random drift PSO) [5.5], MABC (modified ABC) [5.5] and CBA (chaotic bat algorithm ) [54] reported in the literature are also given in Table 11. It can be observed that BFL-PSO achieves the best results in terms of the mean $(15447.40 \$ / \mathrm{h})$, minimal $(15447.32 \$ / \mathrm{h})$ and maximal $(15447.59 \$ / \mathrm{h})$ fuel costs among the five algorithms. MABC gets the best standard deviation (6.04E-08), but its solution accuracy is worse than BFL-PSO.

Table 12 presents the statistical results of BFL-PSO for the 20 unit PED problem. The results of BLPSO [52], CBA [54], BSA (backtracking search algorithm) [56] and CQGSO (continuous quick group search optimizer) [57] reported in the literature are also given in Table 12. From Table 12, BFL-PSO, BLPSO and CQGSO achieve very close results in terms of mean, minimal and maximal fuel costs, i.e. about $62456 \$ / \mathrm{h}$. Moreover, the standard deviation of BFL-PSO is very small.

Based on the above results, it can be said that BLF-PSO can achieve similar or even better results for the PED problems in comparison with the methods in the literature. Therefore, BFL-PSO can be used as an effective method for real-world PED problem.

Table 11: Statistical results of the fuel costs for 6 unit system

\begin{tabular}{lllll}
\hline Algorithm & Mean & Min & Max & SD \\
\hline BFL-PSO & 15447.40 & 15447.32 & 15447.59 & 0.06 \\
BLPSO [52] & 15447.45 & 15447.34 & 15447.67 & 0.09 \\
ST-IRDPSO [5.3] & 15450.7 & 15449.89 & NA & 1.416 \\
MABC [5.5] & 15449.8995 & 15449.8995 & 15449.8995 & $6.04 \mathrm{E}-08$ \\
CBA [54] & 15454.76 & 15450.2381 & 15518.6588 & 2.965 \\
\hline
\end{tabular}

NA means not available in the literature.

The best results are highlighted in bold. 
Table 12: Statistical results of the fuel costs for 20 unit system

\begin{tabular}{lllll}
\hline Algorithm & Mean & Min & Max & SD \\
\hline BFL-PSO & 62456.64 & 62456.57 & 62456.66 & 0.01 \\
BLPSO [52] & 62456.64 & 62456.58 & 62456.65 & 0.01 \\
CBA [54] & 62456.6348 & 62456.6328 & 62501.6714 & 0.3879 \\
BSA [56] & 62457.1517 & 62456.6925 & 62458.1272 & NA \\
CQGSO [5i] $]$ & 62456.6331 & 62456.633 & 62456.63337 & NA \\
\hline
\end{tabular}

NA means not available in the literature.

The best results are highlighted in bold.

\section{Conclusion}

In this paper, a new bee-foraging learning PSO (BFL-PSO) algorithm has been proposed, which is based on the bee-foraging search mechanism. The proposed BFL-PSO has three different search phases, namely employed learning, onlooker learning and scout learning. The employed learning works like the traditional one-phased-based PSO, while the onlooker learning performs strengthened search around the high-quality particle to exploit promising solutions, and the scout learning re-initializes the exhausted particles to introduce new diversity. Therefore, all three search phases contribute to the improvement of the search performance of BFL-PSO

The proposed BFL-PSO has been comprehensively evaluated on the CEC2014 functions, and compared with well-established swarm optimization algorithms, including five PSO algorithms, five $\mathrm{ABC}$ algorithms and two hybrid $\mathrm{PSO}-\mathrm{ABC}$ algorithms. Experimental results demonstrated that BFL-PSO can achieve competitive or even better performance on most test functions, especially on the composite functions with complex landscape. In addition, the effectiveness of the onlooker learning and scout learning in BFL-PSO has been verified through numerical simulations.

In the future, there is much work worth of further investigation. For example, the performance of BFL-PSO is not satisfactory for unimodal functions, and thus one possible work is to combine BFL-PSO with local search technique to further enhance the performance of BFLPSO. In addition, BFL-PSO may be extended for other types of optimization problems such as multi-objective, large-scale and real-world problems.

\section{Acknowledgement}

The first author would like to acknowledge the supports by the Natural Science Foundation of Jiangsu Province, China (BK 20160540). 
Table A1: Comparison results of BFL-PSO with different limit values

\begin{tabular}{|c|c|c|c|c|c|c|c|}
\hline limit & $5 \times N \times D$ & $2 \times N \times D$ & $N \times D$ & $0.5 \times N \times D$ & $0.2 \times N \times D$ & $0.1 \times N \times D$ & $0.05 \times N \times D$ \\
\hline F01 & $3.52 \mathrm{E}+06$ & $2.93 \mathrm{E}+06$ & $2.92 \mathrm{E}+06$ & $3.26 \mathrm{E}+06$ & $2.13 \mathrm{E}+06$ & $1.71 \mathrm{E}+06$ & $2.20 \mathrm{E}+06$ \\
\hline F02 & $9.50 \mathrm{E}+03$ & $8.24 \mathrm{E}+03$ & $1.15 \mathrm{E}+04$ & $9.09 \mathrm{E}+03$ & $9.84 \mathrm{E}+03$ & $1.04 \mathrm{E}+04$ & $9.08 \mathrm{E}+03$ \\
\hline F03 & $3.55 \mathrm{E}+01$ & $3.11 \mathrm{E}+01$ & $1.62 \mathrm{E}+01$ & $1.50 \mathrm{E}+01$ & $1.90 \mathrm{E}+02$ & $6.58 \mathrm{E}+02$ & $9.48 \mathrm{E}+02$ \\
\hline F04 & $8.43 \mathrm{E}+01$ & $8.33 \mathrm{E}+01$ & $8.08 \mathrm{E}+01$ & $8.79 \mathrm{E}+01$ & $8.91 \mathrm{E}+01$ & $8.62 \mathrm{E}+01$ & $9.43 \mathrm{E}+01$ \\
\hline F05 & $2.03 \mathrm{E}+01$ & $2.03 \mathrm{E}+01$ & $2.03 \mathrm{E}+01$ & $2.03 \mathrm{E}+01$ & $2.04 \mathrm{E}+01$ & $2.05 \mathrm{E}+01$ & $2.06 \mathrm{E}+01$ \\
\hline F06 & $1.27 \mathrm{E}+00$ & $1.20 \mathrm{E}+00$ & $1.17 \mathrm{E}+00$ & $1.38 \mathrm{E}+00$ & $1.19 \mathrm{E}+00$ & $9.79 \mathrm{E}-01$ & $7.41 \mathrm{E}-01$ \\
\hline F07 & $0.00 \mathrm{E}+00$ & $0.00 \mathrm{E}+00$ & $3.38 \mathrm{E}-04$ & $0.00 \mathrm{E}+00$ & $1.45 \mathrm{E}-04$ & $0.00 \mathrm{E}+00$ & $1.45 \mathrm{E}-04$ \\
\hline F08 & $1.44 \mathrm{E}+00$ & $1.05 \mathrm{E}+00$ & $8.12 \mathrm{E}-01$ & 3.91E-01 & $2.37 \mathrm{E}-01$ & $4.25 \mathrm{E}-01$ & $5.47 \mathrm{E}-01$ \\
\hline F09 & $2.36 \mathrm{E}+01$ & $2.35 \mathrm{E}+01$ & $2.17 \mathrm{E}+01$ & $1.69 \mathrm{E}+01$ & $9.53 \mathrm{E}+00$ & $7.87 \mathrm{E}+00$ & $1.07 \mathrm{E}+01$ \\
\hline F10 & $3.52 \mathrm{E}+01$ & $2.18 \mathrm{E}+01$ & $1.93 \mathrm{E}+01$ & $1.42 \mathrm{E}+01$ & $7.29 \mathrm{E}+00$ & $9.88 \mathrm{E}+00$ & $1.23 \mathrm{E}+01$ \\
\hline F11 & $1.68 \mathrm{E}+03$ & $1.53 \mathrm{E}+03$ & $1.50 \mathrm{E}+03$ & $1.29 \mathrm{E}+03$ & $4.98 \mathrm{E}+02$ & $2.29 \mathrm{E}+02$ & $2.98 \mathrm{E}+02$ \\
\hline F12 & $3.17 \mathrm{E}-01$ & $3.04 \mathrm{E}-01$ & $3.03 \mathrm{E}-01$ & $3.45 \mathrm{E}-01$ & $3.98 \mathrm{E}-01$ & $5.29 \mathrm{E}-01$ & $7.70 \mathrm{E}-01$ \\
\hline F13 & $1.53 \mathrm{E}-01$ & $1.39 \mathrm{E}-01$ & $1.12 \mathrm{E}-01$ & 8.57E-02 & $6.95 \mathrm{E}-02$ & 7.97E-02 & $1.42 \mathrm{E}-01$ \\
\hline F14 & $2.38 \mathrm{E}-01$ & $2.20 \mathrm{E}-01$ & $2.17 \mathrm{E}-01$ & $2.11 \mathrm{E}-01$ & $2.45 \mathrm{E}-01$ & $2.52 \mathrm{E}-01$ & $2.35 \mathrm{E}-01$ \\
\hline F15 & $4.31 \mathrm{E}+00$ & $4.00 \mathrm{E}+00$ & $3.83 \mathrm{E}+00$ & $3.54 \mathrm{E}+00$ & $3.35 \mathrm{E}+00$ & $3.56 \mathrm{E}+00$ & $8.02 \mathrm{E}+00$ \\
\hline F16 & $8.58 \mathrm{E}+00$ & $8.65 \mathrm{E}+00$ & $8.16 \mathrm{E}+00$ & $7.34 \mathrm{E}+00$ & $6.00 \mathrm{E}+00$ & $5.74 \mathrm{E}+00$ & $7.07 \mathrm{E}+00$ \\
\hline F17 & $3.37 \mathrm{E}+05$ & $3.15 \mathrm{E}+05$ & $3.79 \mathrm{E}+05$ & $3.59 \mathrm{E}+05$ & $3.43 \mathrm{E}+05$ & $3.69 \mathrm{E}+05$ & $4.37 \mathrm{E}+05$ \\
\hline F18 & $9.53 \mathrm{E}+02$ & $6.33 \mathrm{E}+02$ & $1.12 \mathrm{E}+03$ & $1.04 \mathrm{E}+03$ & $8.72 \mathrm{E}+02$ & $8.93 \mathrm{E}+02$ & $7.71 \mathrm{E}+02$ \\
\hline F19 & $4.39 \mathrm{E}+00$ & $4.56 \mathrm{E}+00$ & $4.39 \mathrm{E}+00$ & $4.56 \mathrm{E}+00$ & $4.42 \mathrm{E}+00$ & $4.08 \mathrm{E}+00$ & $3.92 \mathrm{E}+00$ \\
\hline F20 & $6.82 \mathrm{E}+02$ & $9.28 \mathrm{E}+02$ & $6.36 \mathrm{E}+02$ & $1.06 \mathrm{E}+03$ & $2.18 \mathrm{E}+03$ & $1.94 \mathrm{E}+03$ & $2.76 \mathrm{E}+03$ \\
\hline F21 & $6.41 \mathrm{E}+04$ & $5.92 \mathrm{E}+04$ & $6.62 \mathrm{E}+04$ & $6.21 \mathrm{E}+04$ & $9.83 \mathrm{E}+04$ & $1.27 \mathrm{E}+05$ & $1.58 \mathrm{E}+05$ \\
\hline F 22 & $1.08 \mathrm{E}+02$ & $9.77 \mathrm{E}+01$ & $9.72 \mathrm{E}+01$ & $9.56 \mathrm{E}+01$ & $9.05 \mathrm{E}+01$ & $1.05 \mathrm{E}+02$ & $1.12 \mathrm{E}+02$ \\
\hline F 23 & $3.15 \mathrm{E}+02$ & $3.15 \mathrm{E}+02$ & $3.15 \mathrm{E}+02$ & $3.15 \mathrm{E}+02$ & $3.15 \mathrm{E}+02$ & $3.15 \mathrm{E}+02$ & $3.15 \mathrm{E}+02$ \\
\hline F24 & $2.24 \mathrm{E}+02$ & $2.24 \mathrm{E}+02$ & $2.24 \mathrm{E}+02$ & $2.24 \mathrm{E}+02$ & $2.24 \mathrm{E}+02$ & $2.24 \mathrm{E}+02$ & $2.22 \mathrm{E}+02$ \\
\hline F25 & $2.05 \mathrm{E}+02$ & $2.05 \mathrm{E}+02$ & $2.05 \mathrm{E}+02$ & $2.05 \mathrm{E}+02$ & $2.05 \mathrm{E}+02$ & $2.05 \mathrm{E}+02$ & $2.05 \mathrm{E}+02$ \\
\hline F26 & $1.00 \mathrm{E}+02$ & $1.00 \mathrm{E}+02$ & $1.02 \mathrm{E}+02$ & $1.00 \mathrm{E}+02$ & $1.00 \mathrm{E}+02$ & $1.00 \mathrm{E}+02$ & $1.00 \mathrm{E}+02$ \\
\hline $\mathrm{F} 27$ & $3.73 \mathrm{E}+02$ & $3.75 \mathrm{E}+02$ & $3.69 \mathrm{E}+02$ & $3.52 \mathrm{E}+02$ & $3.53 \mathrm{E}+02$ & $3.59 \mathrm{E}+02$ & $3.29 \mathrm{E}+02$ \\
\hline F28 & $8.09 \mathrm{E}+02$ & $8.13 \mathrm{E}+02$ & $8.14 \mathrm{E}+02$ & $8.07 \mathrm{E}+02$ & $8.06 \mathrm{E}+02$ & $8.08 \mathrm{E}+02$ & $8.08 \mathrm{E}+02$ \\
\hline F 29 & $1.25 \mathrm{E}+03$ & $1.26 \mathrm{E}+03$ & $1.34 \mathrm{E}+03$ & $1.29 \mathrm{E}+03$ & $1.39 \mathrm{E}+03$ & $1.58 \mathrm{E}+03$ & $1.47 \mathrm{E}+03$ \\
\hline F30 & $2.30 \mathrm{E}+03$ & $2.40 \mathrm{E}+03$ & $2.27 \mathrm{E}+03$ & $2.19 \mathrm{E}+03$ & $2.72 \mathrm{E}+03$ & $3.00 \mathrm{E}+03$ & $3.17 \mathrm{E}+03$ \\
\hline Friedman rank & 4.82 & 3.92 & 4.23 & 3.25 & 3.48 & 3.88 & 4.42 \\
\hline Final rank & 7 & 4 & 5 & 1 & 2 & 3 & 6 \\
\hline
\end{tabular}

\section{References}

[1] X. Xia, L. Gui, G. He, B. Wei, Y. Zhang, F. Yu, H. Wu, Z.-H. Zhan, An expanded particle swarm optimization based on multi-exemplar and forgetting ability, Information Sciences 508 (2020) 105-120.

[2] X. Yang, L. Chen, X. Xu, W. Wang, Q. Xu, Y. Lin, Z. Zhou, Parameter identification of electrochemical model for vehicular lithium-ion battery based on particle swarm optimization, Energies 10 (2017) 1811.

[3] S. Wang, C. Yu, D. Shi, X. Sun, Research on speed optimization strategy of hybrid electric vehicle queue based on particle swarm optimization, Mathematical Problems in Engineering 2018 (2018). 
[4] Q. Xiang, Y. Yuan, Y. Yu, K. Chen, Rotor position self-sensing of srm using pso-rvm, Energies 11 (2018) 66 .

[5] Y. Xue, B. Xue, M. Zhang, Self-adaptive particle swarm optimization for large-scale feature selection in classification, ACM Transactions on Knowledge Discovery from Data (TKDD) 13 (2019) 1-27.

[6] J. J. Liang, A. K. Qin, P. N. Suganthan, S. Baskar, Comprehensive learning particle swarm optimizer for global optimization of multimodal functions, IEEE transactions on evolutionary computation 10 (2006) 281-295.

[7] Z.-H. Zhan, J. Zhang, Y. Li, Y.-H. Shi, Orthogonal learning particle swarm optimization, IEEE transactions on evolutionary computation 15 (2011) 832-847.

[8] R. Cheng, Y. Jin, A social learning particle swarm optimization algorithm for scalable optimization, Information Sciences 291 (2015) 43-60.

[9] M. R. Tanweer, S. Suresh, N. Sundararajan, Self regulating particle swarm optimization algorithm, Information Sciences 294 (2015) 182-202.

[10] N. Lynn, P. N. Suganthan, Ensemble particle swarm optimizer, Applied Soft Computing 55 (2017) 533-548.

[11] X. Chen, H. Tianfield, C. Mei, W. Du, G. Liu, Biogeography-based learning particle swarm optimization, Soft Computing 21 (2017) 7519-7541.

[12] Y. Gong, J. Li, Y. Zhou, Y. Li, H. S.-H. Chung, Y. Shi, J. Zhang, Genetic learning particle swarm optimization, IEEE transactions on cybernetics 46 (2016) 2277-2290.

[13] X. Xia, Y. Xing, B. Wei, Y. Zhang, X. Li, X. Deng, L. Gui, A fitness-based multi-role particle swarm optimization, Swarm and evolutionary computation 44 (2019) 349-364.

[14] A. Rajasekhar, N. Lynn, S. Das, P. N. Suganthan, Computing with the collective intelligence of honey bees-a survey, Swarm and Evolutionary Computation 32 (2017) 25-48.

[15] W.-F. Gao, L.-L. Huang, S.-Y. Liu, C. Dai, Artificial bee colony algorithm based on information learning, IEEE transactions on cybernetics 45 (2015) 2827-2839.

[16] X. Chen, H. Tianfield, K. Li, Self-adaptive differential artificial bee colony algorithm for global optimization problems, Swarm and Evolutionary Computation 45 (2019) 70-91. 
[17] J. Liang, B. Qu, P. Suganthan, Problem definitions and evaluation criteria for the cec 2014 special session and competition on single objective real-parameter numerical optimization, Computational Intelligence Laboratory, Zhengzhou University, Zhengzhou China and Technical Report, Nanyang Technological University, Singapore (2013).

[18] D. Wang, D. Tan, L. Liu, Particle swarm optimization algorithm: an overview, Soft Computing 22 (2018) 387-408.

[19] M. R. Bonyadi, Z. Michalewicz, Particle swarm optimization for single objective continuous space problems: a review, 2017.

[20] M. Taherkhani, R. Safabakhsh, A novel stability-based adaptive inertia weight for particle swarm optimization, Applied Soft Computing 38 (2016) 281-295.

[21] K. Chen, F. Zhou, L. Yin, S. Wang, Y. Wang, F. Wan, A hybrid particle swarm optimizer with sine cosine acceleration coefficients, Information Sciences 422 (2018) 218-241.

[22] B. Wei, X. Xia, F. Yu, Y. Zhang, X. Xu, H. Wu, L. Gui, G. He, Multiple adaptive strategies based particle swarm optimization algorithm, Swarm and Evolutionary Computation (2020) 100731.

[23] A. Lin, W. Sun, H. Yu, G. Wu, H. Tang, Global genetic learning particle swarm optimization with diversity enhancement by ring topology, Swarm and evolutionary computation 44 (2019) 571-583.

[24] W. Fang, J. Sun, H. Chen, X. Wu, A decentralized quantum-inspired particle swarm optimization algorithm with cellular structured population, Information Sciences 330 (2016) $19-48$.

[25] N. Lynn, P. N. Suganthan, Heterogeneous comprehensive learning particle swarm optimization with enhanced exploration and exploitation, Swarm and Evolutionary Computation 24 (2015) 11-24.

[26] W. Li, X. Meng, Y. Huang, Z.-H. Fu, Multipopulation cooperative particle swarm optimization with a mixed mutation strategy, Information Sciences 529 (2020) 179-196.

[27] Q. Qin, S. Cheng, Q. Zhang, L. Li, Y. Shi, Particle swarm optimization with interswarm interactive learning strategy, IEEE transactions on cybernetics 46 (2016) 2238-2251. 
[28] G. Xu, Q. Cui, X. Shi, H. Ge, Z.-H. Zhan, H. P. Lee, Y. Liang, R. Tai, C. Wu, Particle swarm optimization based on dimensional learning strategy, Swarm and Evolutionary Computation 45 (2019) 33-51.

[29] Q. Yang, W.-N. Chen, J. Da Deng, Y. Li, T. Gu, J. Zhang, A level-based learning swarm optimizer for large-scale optimization, IEEE Transactions on Evolutionary Computation 22 (2018) 578-594.

[30] W. H. Lim, N. A. M. Isa, Bidirectional teaching and peer-learning particle swarm optimization, Information Sciences 280 (2014) 111-134.

[31] T. Liu, L. Jiao, W. Ma, J. Ma, R. Shang, Cultural quantum-behaved particle swarm optimization for environmental/economic dispatch, Applied Soft Computing 48 (2016) 597611.

[32] R. Jensi, G. W. Jiji, An enhanced particle swarm optimization with levy flight for global optimization, Applied Soft Computing 43 (2016) 248-261.

[33] H. Ouyang, L. Gao, X. Kong, S. Li, D. Zou, Hybrid harmony search particle swarm optimization with global dimension selection, Information Sciences 346 (2016) 318-337.

[34] A. Meng, Z. Li, H. Yin, S. Chen, Z. Guo, Accelerating particle swarm optimization using crisscross search, Information Sciences 329 (2016) 52-72.

[35] X. Zhang, X. Wang, Q. Kang, J. Cheng, Differential mutation and novel social learning particle swarm optimization algorithm, Information Sciences 480 (2019) 109-129.

[36] X. Shi, Y. Li, H. Li, R. Guan, L. Wang, Y. Liang, An integrated algorithm based on artificial bee colony and particle swarm optimization, in: 2010 Sixth international conference on natural computation, volume 5, IEEE, 2010, pp. 2586-2590.

[37] M. S. Kiran, M. Gündüz, A recombination-based hybridization of particle swarm optimization and artificial bee colony algorithm for continuous optimization problems, Applied Soft Computing 13 (2013) 2188-2203.

[38] L. Vitorino, S. F. Ribeiro, C. J. Bastos-Filho, A mechanism based on artificial bee colony to generate diversity in particle swarm optimization, Neurocomputing 148 (2015) 39-45. 
[39] Z. Li, W. Wang, Y. Yan, Z. Li, Ps-abc: A hybrid algorithm based on particle swarm and artificial bee colony for high-dimensional optimization problems, Expert Systems with Applications 42 (2015) 8881-8895.

[40] M. El-Abd, On the hybridization of the artificial bee colony and particle swarm optimization algorithms, Journal of Artificial Intelligence and Soft Computing Research 2 (2012).

[41] W. Chun-Feng, L. Kui, S. Pei-Ping, Hybrid artificial bee colony algorithm and particle swarm search for global optimization, Mathematical Problems in Engineering 2014 (2014).

[42] N. Imanian, M. E. Shiri, P. Moradi, Velocity based artificial bee colony algorithm for high dimensional continuous optimization problems, Engineering Applications of Artificial Intelligence 36 (2014) 148-163.

[43] Y. Xiang, Y. Peng, Y. Zhong, Z. Chen, X. Lu, X. Zhong, A particle swarm inspired multi-elitist artificial bee colony algorithm for real-parameter optimization, Computational Optimization and Applications 57 (2014) 493-516.

[44] H. Sharma, S. Sharma, S. Kumar, Lbest gbest artificial bee colony algorithm, in: 2016 International conference on advances in computing, communications and informatics (ICACCI), IEEE, 2016, pp. 893-898.

[45] X. Chen, B. Xu, C. Mei, Y. Ding, K. Li, Teaching-learning-based artificial bee colony for solar photovoltaic parameter estimation, Applied energy 212 (2018) 1578-1588.

[46] D. Karaboga, B. Basturk, A powerful and efficient algorithm for numerical function optimization: artificial bee colony (abc) algorithm, Journal of global optimization 39 (2007) 459-471.

[47] G. Zhu, S. Kwong, Gbest-guided artificial bee colony algorithm for numerical function optimization, Applied mathematics and computation 217 (2010) 3166-3173.

[48] D. Karaboga, B. Gorkemli, A quick artificial bee colony (qabc) algorithm and its performance on optimization problems, Applied Soft Computing 23 (2014) 227-238.

[49] M. S. Kiran, H. Hakli, M. Gunduz, H. Uguz, Artificial bee colony algorithm with variable search strategy for continuous optimization, Information Sciences 300 (2015) 140-157. 
[50] L. Cui, G. Li, Q. Lin, Z. Du, W. Gao, J. Chen, N. Lu, A novel artificial bee colony algorithm with depth-first search framework and elite-guided search equation, Information Sciences 367 (2016) 1012-1044.

[51] X. Chen, Novel dual-population adaptive differential evolution algorithm for large-scale multi-fuel economic dispatch with valve-point effects, Energy (2020) 117874.

[52] X. Chen, B. Xu, W. Du, An improved particle swarm optimization with biogeography-based learning strategy for economic dispatch problems, Complexity 2018 (2018).

[53] W. T. Elsayed, Y. G. Hegazy, M. S. El-bages, F. M. Bendary, Improved random drift particle swarm optimization with self-adaptive mechanism for solving the power economic dispatch problem, IEEE Transactions on Industrial Informatics 13 (2017) 1017-1026.

[54] B. Adarsh, T. Raghunathan, T. Jayabarathi, X.-S. Yang, Economic dispatch using chaotic bat algorithm, Energy 96 (2016) 666-675.

[55] D. C. Secui, A new modified artificial bee colony algorithm for the economic dispatch problem, Energy Conversion and Management 89 (2015) 43-62.

[56] M. Modiri-Delshad, N. A. Rahim, Solving non-convex economic dispatch problem via backtracking search algorithm, Energy 77 (2014) 372-381.

[57] M. Moradi-Dalvand, B. Mohammadi-Ivatloo, A. Najafi, A. Rabiee, Continuous quick group search optimizer for solving non-convex economic dispatch problems, Electric Power Systems Research 93 (2012) 93-105. 